INSTITUT NATIONAL DE LA STATISTIQUE ET DES ETUDES ECONOMIQUES

Série des Documents de Travail du CREST

(Centre de Recherche en Economie et Statistique)

\author{
$n^{\circ}$ 2010-15 \\ Optimal Redistributive Taxation \\ with both Extensive and Intensive \\ Responses
}

\author{
L. JACQUET - E. LEHMANN \\ B. VAN DER LINDEN
}

Les documents de travail ne reflètent pas la position de l'INSEE et n'engagent que leurs auteurs.

Working papers do not reflect the position of INSEE but only the views of the authors. 


\title{
Optimal Redistributive Taxation with both Extensive and Intensive Responses*
}

\author{
Laurence JACQUET ${ }^{1}$, Etienne LEHMANN ${ }^{2}$, Bruno VAN DER LINDEN ${ }^{3}$
}

\begin{abstract}
We derive a general optimal income tax formula when individuals respond along both the intensive and extensive margins and when income effects can prevail. Individuals are heterogeneous across two dimensions: their skill and their disutility of participation. Preferences over consumption and work effort can differ with respect to the level of skill, with only the Spence-Mirrlees condition being imposed. Employing a new tax perturbation approach that integrates the nonlinearity of the tax function into the behavioral elasticities, we derive a fairly mild condition for optimal marginal tax rates to be nonnegative everywhere. Numerical simulations using U.S. data confirm the mildness of our conditions. The extensive margin strongly reduces the level of optimal marginal tax rates
\end{abstract}

\section{Résumé}

Nous déterminons une formule générale de taxation optimale pour le cas où les individus ont des réponses intensives et extensives de leur offre de travail et où des effets revenus peuvent survenir. Les individus diffèrent selon deux caractéristiques : leur productivité et leur désutilité à participer. Des individus de productivité différents peuvent avoir une fonction d'utilité différente tant que la condition de Spence-Mirrlees reste vérifiée. En utilisant une nouvelle méthode de perturbation de la fonction de taxe qui intègre dans la définition des élasticités comportementales les non-linéarités de la fonction de taxe, nous obtenons une condition suffisante assez peu restrictive qui garantit que les taux marginaux optimaux sont partout positifs ou nuls. Nos simulations numériques basées sur des données américaines confirment le caractère plausible de notre condition suffisante. Elles montrent également que l'introduction d'une marge extensive réduit singulièrement le niveau des taux marginaux optimaux.

JEL Classification: H21, H23.

Keywords: Optimal tax formula, Tax perturbation, Random participation.

\footnotetext{
* We thank for their comments participants at seminars at GREQAM-IDEP in Marseilles, IAP CORE/Ghent/KULeuven seminar in Ghent, CREST, BETA in Strasbourg, NHH, Uppsala, Louis-André GerardVaret meeting in Marseilles, NTNU in Trondheim, the CESifo Norwegian-German seminar on public Economics, the ERASMUS university in Rotterdam the UiB in Bergen, the Toulouse School of Economics, the CESifo public economics meeting the Canadian Public Economics Group meeting and the IIPF 2010 meeting in Uppsala with a particular mention to Sören Blomquist, Robin Boadway, Craig Brett, Pierre Cahuc, Philippe de Donder, Nicolas Gravel, Bas Jacobs, Guy Laroque, Patrick Pintus, Ray Rees, Emmanuel Saez, François Salanié, Agnar Sandmo, Laurent Simula, Alain Trannoy, Matti Tuomala and Floris Zoutman. Any errors are ours. Laurence Jacquet would like to thank Skipsreder J.R. Olsen og hustrus legat to NHH. This research has been funded by the Belgian Program on Interuniversity Poles of Attraction (P6/07 Economic Policy and Finance in the Global Economy: Equilibrium Analysis and Social Evaluation) initiated by the Belgian State, Prime Minister's Office, Science Policy Programming.
}

1 Norvegian School of Economics and Business Administration, (Address: Norwegian School of Economics and Business Administration (NHH), Economics Department, Helleveien 30, 5045 Bergen, Norway). Email: laurence.jacquet@nhh.no Laurence Jacquet is also research fellow at CESifo, Hoover Chair and IRES Université Catholique de Louvain.

2 CREST -INSEE, (Address: CREST-INSEE, Timbre J360, 15 boulevard Gabriel Péri, 92245, Malakoff Cedex, France). Email: etienne.lehmann@ensae.fr. Etienne Lehmann is also research fellow at IRES - Université Catholique de Louvain, IZA and IDEP.

3 IRES - Université Catholique de Louvain, FNRS, ERMES - Université Paris 2, (Address: IRES, Université Catholique de Louvain, Place Montesquieu 3, B1348, Louvain-la-Neuve, Belgium). Email: bruno.vanderlinden@uclouvain.be, Bruno Van der Linden is also research fellow at IZA 


\section{Introduction}

When labor supply is modeled along the intensive (in-work effort) margin only, the theory of optimal income taxation recommends that the marginal tax rates be almost everywhere positive 11 When individuals respond along both the intensive and extensive (participation) margins, negative participation tax rates ${ }^{2}$ may prevail as numerically derived in the seminal contribution by Saez (2002). As a first contribution, we provide analytical results about the sign of optimal marginal tax rates in a model with both the intensive and extensive margins. To the best of our knowledge, this has not been done in the literature. This paper analytically derives a fairly mild sufficient condition under which optimal marginal tax rates are almost everywhere positive.

For this purpose, we consider an economy where individuals are heterogeneously endowed with two unobserved characteristics: their skill level and disutility of participation. Because of the former heterogeneity, employed workers typically choose different earnings levels, while because of the latter heterogeneity, at any skill level, only some individuals choose to work. The government then faces a multidimensional screening problem of the "random participation" type (Rochet and Stole (2002)). It can only condition taxation on endogenous earnings and not on the exogenous characteristics whose heterogeneity in the population lies at the origin of the redistribution problem.

We show that optimal marginal tax rates are nonnegative if the ratio of one minus the social welfare weight to the extensive behavioral response increases along the skill distribution. If the intensive margin is shut down, the optimal equity-efficiency trade-off equalizes the participation tax to this ratio at each skill level. If this ratio is increasing in the skill level, so does the participation tax. If now the intensive margin is taken into account, positive marginal tax rates distort intensive responses downwards. Consequently, the optimal equity-efficiency trade-off takes this additional distortion into account and opts for lower but still positive marginal tax rates (except at the two extremes of the skill distribution). While our sufficient condition is expressed in terms of endogenous variables, we discuss its relevance in practice and provide examples of specifications on primitives where this condition holds. For instance, when the government has a Maximin objective, the restrictions imposed by our sufficient condition are fairly weak.

In order to derive the condition that ensures positive marginal tax rates, this paper introduces a new method to sign the distortions along the intensive margin in any screening model with random participation. This new technique, that can largely be used in other contexts of

\footnotetext{
${ }^{1}$ See, e.g., Mirrlees (1971), Sadka (1976), Seade (1982), Werning (2000) or Hellwig (2007). See however the counterexamples of Choné and Laroque (2009b).

${ }^{2}$ The participation tax rate equals the tax level plus the benefit for the nonemployed.
} 
monopoly screening with random participation, is the second contribution of our paper.

Since Mirrlees (1971), the optimal tax problem is usually solved by searching for the best incentive-compatible allocation using optimal control. While this method has proved successful, it lacks economic intuition. A natural alternative consists in computing the effects of a perturbation in the optimal tax schedule. However, this "tax perturbation" approach is not often adopted, one reason being the following "circular process": Due to the nonlinearity of the tax schedule, when labor supply responds to a tax perturbation, the induced change in gross income affects in turn the marginal tax rate, thereby generating a further labor supply response. Our third contribution is to directly derive the optimal tax formula thanks to a new tax perturbation approach by defining behavioral elasticities in a way that integrates this circular process. We express optimal marginal rates as a function of the social welfare weights, the skill distribution and the behavioral elasticities. Our decomposition generalizes previous results by allowing for income effects and extensive margin responses. We verify that the Mirrleesian approach leads to the same formula.

In the presence of income effects, the literature has established that the optimal marginal tax rates are ceteris paribus increasing in the uncompensated elasticity of the labor supply, which is puzzling (see, for instance, Equation (25) in Saez (2001)). We show that marginal tax rates are actually increasing in the elasticity of gross income with respect to the skill level. The latter elasticity equals one plus the uncompensated elasticity of the labor supply only when preferences over consumption and in-work effort are homogeneous and when gross income is the product of the intensive in-work effort times the skill level. Our fourth contribution is to clarify this point by relaxing these usual assumptions, keeping only the Spence-Mirrlees restriction.

Finally, using U.S. data, we check whether our sufficient condition for nonnegative marginal tax rates is empirically reasonable and we illustrate the quantitative implications of our optimal tax formula. We find that marginal tax rates are always positive and that our sufficient condition is largely satisfied. Moreover, the standard U-shape profile obtained in the Mirrlees model is still valid when both margins are considered. However, introducing the extensive margin has a quantitatively important impact. In our benchmark simulation, the mean of the marginal tax rates between 0 and $\$ 100,000$ per year is reduced by 11.3 percentage points under the Benthamite criterion and by 36.5 percentage points under Maximin when the extensive margin is introduced. We also find that, for the least skilled workers, participation taxes are typically negative under the Benthamite criterion, while they are always positive under Maximin 3 Under Benthamite preferences, with a strictly positive lower bound for the earnings distribution. 4 our simulations

\footnotetext{
${ }^{3}$ The literature on optimal taxation in the pure extensive model has typically found the latter (e.g. Choné and Laroque (2005)). The optimality of a negative participation tax at the bottom of the earnings distribution is interpreted as a case for an Earned Income Tax Credit (EITC) rather than an Negative Income Tax (NIT) (see Saez (2002)).

${ }^{4}$ We assume a strictly positive minimum for the skill distribution.
} 
show a negative participation tax rate at this minimum (as for the EITC) and positive marginal tax rates (as for the NIT). In such case, the optimal tax schedule is a third way between NIT and EITC with negative participation taxes at the low end of the skill distribution and positive marginal tax rates everywhere.

For many years following Mirrlees' (1971) seminal work, the various theoretical developments focused on useful technical refinements but provided little economic intuitions. The first important advance was made when Atkinson (1990), Piketty (1997) and Diamond (1998) reexpressed optimality conditions derived from the Mirrlees model in terms of behavioral elasticities in the absence of income effects. Saez (2001) provided a second important advance by deriving an optimal tax formula using the tax perturbation approach 5 He took into account the abovementioned "circular process" by expressing the optimal tax formula in terms of the unappealing notion of a "virtual" 6 earnings distribution and verified the consistency of his solution with that in Mirrlees (1971). Further, Saez (2001) allowed for income effects. In this study, we avoid the use of virtual densities because of our redefinition of the behavioral elasticities.

The above-mentioned studies neglected labor supply responses along the extensive margin, while the empirical labor supply literature emphasizes that labor supply responses along the extensive margin are much more important (see, e.g., Heckman (1993)). Saez (2002) derived an optimal tax formula in an economy with both intensive and extensive margins. Saez (2002) focused on the EITC/NIT debate about whether the working poor should receive greater transfers than nonemployed individuals (i.e. about the sign of the participation tax at the bottom), while we discuss the conditions under which marginal tax rates should be nonnegative. Moreover, our formula allows for income effects.7 He developed a model where agents choose from a finite set of occupations, each associated with an exogenous level of earnings. We treat the intensive margin in a continuous way, which we think is more appropriate for the study of marginal tax rates.

Kleven and Kreiner (2006) consider a model with both margins. Their model as ours exhibits a bi-dimensional heterogeneity. However, we allow preferences between consumption and work effort to differ across skill levels. Moreover, they focus on the computation of the marginal

\footnotetext{
${ }^{5}$ Christiansen (1981) first introduced the tax perturbation approach. However, he did not derive any implications for the optimal income tax, his focus being instead on the optimal provision of public goods and the structure of commodity taxation. Revecz (1989) also proposed a method to derive an optimal income tax formula in terms of elasticities but did not consider the above-mentioned circular process. Hence, his solution was inconsistent with Mirrlees (1971) (see Revecz (2003) and Saez (2003)). Using a tax perturbation method, Piketty (1997) derived the optimal nonlinear income tax schedule under Maximin. However, he too neglected to take into account the circular process, though this had no consequence as he assumed away the income effects. Roberts (2000) derived an optimal tax formula under Benthamite preferences.

${ }^{6}$ Saez (2001, p.215) defines the virtual density at earnings level $z$ as "the density of incomes that would take place at $z$ if the tax schedule $T($.$) were replaced by the linear tax schedule tangent to T($.$) at level z$ ".

${ }^{7}$ The formal model in the appendix in Saez (2002) allows for the possibility of income effects. Moreover, the appendix in Saez (2000) (the NBER version of Saez (2002)) extends his optimal tax formula with both extensive and intensive responses to the case of a continuum of earnings but still without income effects.
} 
cost of public funds, while we are interested in the design of the optimal income tax schedule. Immervoll et alii (2007) calibrate a model similar to Kleven and Kreiner (2006) on 15 European countries to compute the effects of two prototypical tax reforms. Kleven, Kreiner and Saez (2009) investigate the optimal taxation of couples in a model where primary earners respond along their intensive margin and their spouse respond along their extensive margin. Secondary earners are equally productive but have heterogeneous opportunity cost of work. Kleven, Kreiner and Saez investigate whether the tax rate on one person should depend on the earnings of the spouse. Finally, Boone and Bovenberg (2004) introduce search decisions in the Mirrlees model. Their specification of the search technology implies that any individual with a skill level above (below) an endogenous threshold searches at the maximum intensity (does not search).

Section II presents the model. Section III derives the optimal tax formula in terms of behavioral elasticities using the tax perturbation method. This section also compares the obtained tax formula with the existing literature. Section IV provides a sufficient condition to ensure nonnegative optimal marginal tax rates and gives examples where this condition is satisfied. Section $\mathrm{V}$ presents the simulations for the U.S. In the appendix, we develop the formal model. In particular, we solve for the optimal allocations using the typical optimal control approach. We then verify that this solution is consistent with that derived in the main body of the text.

\section{The model}

\section{II.1 Individuals}

Each individual derives utility from consumption $C$ and disutility from labor supply or effort $L$. More effort implies higher earnings $Y$, the relationship between the two also depends on the individual's skill endowment $w$. The literature typically assumes that $Y=w \times L$. To avoid this unnecessary restriction on the technology, we express individuals' preferences in terms of the observables $(C$ and $Y$ ) and the individuals' exogenous characteristics (particularly $w$ ). This also enables us to consider cases where the preferences over consumption $C$ and effort $L$ are skill dependent. The skill endowments are exogenous, heterogeneous and unobserved by government. Hence, consumption $C$ is related to earnings $Y$ through the tax function $C=Y-T(Y)$.

The empirical literature has emphasized that a significant part of the labor supply responses to tax reforms are concentrated along the extensive margin. We integrate this feature by considering a specific disutility of participation, which makes a difference in the level of utility only between workers (for whom $Y>0$ ) and the nonemployed (for whom $Y=0$ ). This disutility may arise from commuting, job-search effort, or the reduced amount of time available for home production. However, for some people, employment has a value per se, as at least some enjoy working (see, e.g., Polachek and Siebert (1993, p. 101)). Some individuals would even feel stigmatized if they had no job. Let $\chi$ denote an individual's disutility of participation net of this 
intrinsic job value. We assume that people are endowed with different positive or negative (net) disutility of participation $\chi$. As for the skill endowment, $\chi$ is exogenous and unobserved by the government. Because of this additional heterogeneity, individuals with the same skill level may take different participation decisions. This is consistent with the observation that in all OECD countries, skill-specific employment rates always lie inside $(0,1)$.

For tractability, we require that the intensive labor supply decisions $Y$ of individuals that have chosen to work depend only on their skill and not on their net disutility of participation. To obtain this simplification, we need to impose some separability in individuals' preferences. We specify the utility function of an individual of type $(w, \chi)$ as:

$$
\mathcal{U}(C, Y, w)-\mathbb{I}_{Y>0} \cdot \chi
$$

where $\mathbb{I}_{Y>0}$ is an indicator variable equal to one if the individual works and zero otherwise. The gross utility function $\mathcal{U}(., .,$.$) is twice-continuously differentiable and concave with respect$ to $(C, Y)$. Individuals derive utility from consumption $C$ and disutility from labor supply, so $\mathcal{U}_{C}^{\prime}>0>\mathcal{U}_{Y}^{\prime}$. This utility function allows preferences over $C$ and $Y$ to vary with $w$. Finally, we impose the strict-single crossing (Spence-Mirrlees) condition. We assume that, starting from any positive level of consumption and earnings, more skilled workers need to be compensated with a smaller increase in their consumption to accept a unit rise in earnings. This implies that the marginal rate of substitution $-\mathcal{U}_{Y}^{\prime}(C, Y, w) / \mathcal{U}_{C}^{\prime}(C, Y, w)$ decreases in the skill level. Hence we have:

$$
\mathcal{U}_{Y w}^{\prime \prime}(C, Y, w) \cdot \mathcal{U}_{C}^{\prime}(C, Y, w)-\mathcal{U}_{C w}^{\prime \prime}(C, Y, w) \cdot \mathcal{U}_{Y}^{\prime}(C, Y, w)>0
$$

The distribution of skills is described by the density $f($.$) , which is continuous and positive$ over the support $\left[w_{0}, w_{1}\right]$, with $0<w_{0}<w_{1} \leq+\infty$. It is worth noting that the lowest skill is positive. The size of the total population is normalized to 1 so $\int_{w_{0}}^{w_{1}} f(w) d w=1$. The distribution of $\chi$ conditional on the skill level $w$ is described by the conditional density $k(., w)$ and the cumulated density function $K(\chi, w) \stackrel{\text { def }}{\equiv} \int_{-\infty}^{\chi} k(x, w) d x$. The density $k(.,$.$) is continuously$ differentiable. It is worth noting that we do not assume independence between $w$ and $\chi$. The support of the distribution is $\left(-\infty, \chi^{\max }\right]$, with $\chi^{\max } \leq+\infty$. The assumption about the lower bound is made for tractability as it ensures a positive mass of employed individuals at each skill level.

Each agent solves the following maximization problem:

$$
\max _{Y} \mathcal{U}(Y-T(Y), Y, w)-\mathbb{I}_{Y>0} \cdot \chi
$$

where the choice of $Y$ can be decomposed into a participation decision (i.e., $Y=0$ or $Y>0$ ) and an intensive choice (i.e., the value of $Y$ when $Y>0)$. For a worker of type $(w, \chi)$, selecting a 
positive earnings level $Y$ to maximize $\mathcal{U}(C, Y, w)$ subject to $C=Y-T(Y)$ amounts to solving:

$$
U_{w} \stackrel{\text { def }}{=} \max _{Y} \mathcal{U}(Y-T(Y), Y, w)
$$

In particular, two workers with the same skill level but with a different disutility of participation $\chi$ face the same intensive choice program, thereby taking the same decisions along the intensive margin 8 Let $Y_{w}$ be the intensive choice of a worker of skill $w$, and let $C_{w}$ be the corresponding consumption level, so $C_{w}=Y_{w}-T\left(Y_{w}\right)$. The gross utility of workers of skill $w$ therefore equals $U_{w}=\mathcal{U}\left(C_{w}, Y_{w}, w\right)$. We ignore the non-negativity constraint on $Y_{w}$ when solving the intensive choice program. We verify in our simulations that the minimum of the earnings distribution is always positive (given that we assume $w_{0}>0$ ). Therefore, the possibility of bunching due to the nonnegativity constraint can be neglected.

We now turn to the participation decisions. Let $b=-T(0)$ denote the consumption level for the nonemployed. We refer to $b$ as the welfare benefit. If an individual of type $(w, \chi)$ chooses to work, she obtains utility $U_{w}-\chi$. If she chooses not to participate, she obtains $\mathcal{U}(b, 0, w)$. An individual of type $(w, \chi)$ then chooses to work if $\chi \leq U_{w}-\mathcal{U}(b, 0, w)$. Therefore, the mass of workers of skill $w$ is given by $h(w)$ defined as:

$$
h(w) \stackrel{\text { def }}{\equiv} K\left(U_{w}-\mathcal{U}(b, 0, w), w\right) \cdot f(w)
$$

with some abuse of notation as $h(w)$ does not make explicit the dependence of $h($.$) with respect$ to $b$ and $U_{w}$. The function $h(w)$ is twice-continuously differentiable, increasing in $U_{w}$ and decreasing in $b$, with respective derivatives $h_{U}^{\prime}(w)$ and $h_{b}^{\prime}(w)$ given by

$h_{U}^{\prime}(w)=k\left(U_{w}-\mathcal{U}(b, 0, w), w\right) \cdot f(w) \quad$ and $\quad h_{b}^{\prime}(w)=-\mathcal{U}_{C}^{\prime}(b, 0, w) \cdot k\left(U_{w}-\mathcal{U}(b, 0, w), w\right) \cdot f(w)$

The number of workers of skill less than $w$ is $H(w)=\int_{w_{0}}^{w} h(n) \cdot d n$. There are then $H\left(w_{1}\right)$ employed individuals and $1-H\left(w_{1}\right)$ nonemployed individuals.

\footnotetext{
${ }^{8}$ The key assumption for this result is that preferences over consumption and earnings for employed agents vary only with skill and do not depend on the net disutility of participation $\chi$. Such a property is obtained under weakly separable preferences of the form:

$$
W(C, Y, w, \chi)= \begin{cases}V(\mathcal{U}(C, Y, w), w, \chi) & \text { if } \quad Y>0 \\ \mathcal{U}^{0}(C, w, \chi) & Y=0\end{cases}
$$

where $W$ is discontinuous at $Y=0, V(., .,$.$) is an aggregator increasing in its first argument, function \mathcal{U}(., .,$. verifies $\mathcal{U}_{C}^{\prime}>0>\mathcal{U}_{Y}^{\prime}$ and 2 function $\mathcal{U}^{0}(., .,$.$) describes the preference of the nonemployed and increases in its$ first argument, functions $\mathcal{U}(., .,),. \mathcal{U}^{0}(., .,$.$) and V(., .,$.$) are twice-continuously differentiable over respectively$ $\mathbb{R}^{+} \times \mathbb{R}^{+} \times\left[w_{0}, w_{1}\right], \mathbb{R}^{+} \times\left[w_{0}, w_{1}\right] \times \mathbb{R}^{+}$and $\mathbb{R} \times\left[w_{0}, w_{1}\right] \times\left(-\infty, \chi^{\max }\right]$, and finally, the assumption that for given levels of $C, Y, w$ and $b$, the function $\chi \mapsto V(\mathcal{U}(C, Y, w), w, \chi)-\mathcal{U}^{0}(b, w, \chi)$ is decreasing and admits a positive limit whenever $\chi$ tends to $-\infty$. All results derived in this paper can be obtained under this more general specification, the additional difficulty being only notational.
} 


\section{II.2 Behavioral elasticities}

We define the behavioral elasticities from the intensive choice program (3) and the extensive margin decision (4). When the tax function is differentiable, (3) implies:

$$
1-T^{\prime}\left(Y_{w}\right)=-\frac{\mathcal{U}_{Y}^{\prime}}{\mathcal{U}_{C}^{\prime}}
$$

where the derivatives of $\mathcal{U}($.$) are evaluated at \left(C_{w}, Y_{w}, w\right)$. When the tax function is twice differentiable, the second-order condition is:

$$
\mathcal{U}_{Y Y}^{\prime \prime}-2\left(\frac{\mathcal{U}_{Y}^{\prime}}{\mathcal{U}_{C}^{\prime}}\right) \mathcal{U}_{C Y}^{\prime \prime}+\left(\frac{\mathcal{U}_{Y}^{\prime}}{\mathcal{U}_{C}^{\prime}}\right)^{2} \mathcal{U}_{C C}^{\prime \prime}-T^{\prime \prime}\left(Y_{w}\right) \cdot \mathcal{U}_{C}^{\prime} \leq 0
$$

As function $\mathcal{U}(., ., w)$ is concave, the second-order condition (6) is satisfied when the tax function is linear or convex or is not "too concave". Whenever (6) strictly holds, which we henceforth assume throughout the remainder of this section, the first-order condition (5) implicitly defines $\mathrm{9}^{9}$ earnings $Y_{w}$ as a function of the skill level and the tax function. The elasticity $\alpha_{w}$ of earnings with respect to the skill level equals:10

$$
\alpha_{w} \stackrel{\text { def }}{\equiv} \frac{w}{Y_{w}} \cdot \dot{Y}_{w}=-\frac{\frac{w}{Y_{w}} \cdot\left[\mathcal{U}_{Y w}^{\prime \prime} \cdot \mathcal{U}_{C}^{\prime}-\mathcal{U}_{C w}^{\prime \prime} \cdot \mathcal{U}_{Y}^{\prime}\right]}{\left[\mathcal{U}_{Y Y}^{\prime \prime}-2\left(\frac{\mathcal{U}_{Y}^{\prime}}{\mathcal{U}_{c}^{\prime}}\right) \mathcal{U}_{C Y}^{\prime \prime}+\left(\frac{\mathcal{U}_{Y}^{\prime}}{\mathcal{U}_{c}^{\prime}}\right)^{2} \mathcal{U}_{C C}^{\prime \prime}-T^{\prime \prime}\left(Y_{w}\right) \cdot \mathcal{U}_{C}^{\prime}\right] \cdot \mathcal{U}_{C}^{\prime}}
$$

Let $\hat{h}(Y)$ and $\hat{H}(Y)$ denote respectively the density and cumulated density function of the earnings distribution among employed individuals, with $\partial \hat{H}(Y) / \partial Y=\hat{h}(Y)$. For all skill levels, one has $\hat{H}\left(Y_{w}\right) \equiv H(w)$. From Equation (7), $h(w)$ and $\hat{h}\left(Y_{w}\right)$ are thus related by:

$$
\frac{Y_{w}}{w} \cdot \alpha_{w} \cdot \hat{h}\left(Y_{w}\right) \equiv h(w)
$$

If the left-hand side of (6) is nil, then the function $Y \mapsto \mathcal{U}(Y-T(Y), Y, w)$ becomes typically constant around $w$. Therefore, individuals of type $w$ are indifferent between a range of earnings levels, so the function $n \mapsto Y_{n}$ becomes discontinuous at skill $n=w$ and program (3) admit multiple solutions for workers of skill $w$. The same phenomenon also occurs when the tax function is downward discontinuous at $Y_{w}\left(T^{\prime \prime}(Y)\right.$ tends to minus infinity, so (6) is violated). Conversely, bunching of types occurs when $\alpha_{w}=0$ (i.e. $T^{\prime \prime}(Y)$ tends to plus infinity). This corresponds to a kink in the tax function. From here on, we assume that $T($.$) is differentiable$ and hence exclude bunching. However, this assumption is relaxed in the appendix, where we

\footnotetext{
${ }^{9}$ In addition, one has to assume that among the possible multiple local maxima of $Y \mapsto U(Y-T(Y), Y, w)$, a single maximum corresponds to the global maximum. If program $Y \mapsto U\left(Y-T(Y), Y, w^{*}\right)$ admits two global maxima for a skill level $w^{*}$, workers of a skill level $w$ slightly above (below) $w^{*}$ would strictly prefer the higher (lower) maximum because of the strict single-crossing condition (2). Hence, function $w \mapsto Y_{w}$ exhibits a discontinuity at skill $w^{*}$. Moreover, once again through the strict single-crossing condition, function $w \mapsto Y_{w}$ is nondecreasing. Therefore, it is discontinuous on a set of skill levels that is at worst countable (and at best empty). Because the skill distribution is assumed continuous without any mass point, the latter set is of zero measure.

${ }^{10}$ See Appendix A.
} 
solve the model in terms of incentive-compatible allocations and consider what happens when bunching takes place.

We now consider different elementary tax reforms and compute how they affect the intensive (3) and extensive (4) choices. The first elementary tax reform captures the substitution effect around the actual tax schedule. The marginal tax rate $T^{\prime}(Y)$ is decreased by a small amount $\tau$ over the range of earnings $\left[Y_{w}-\delta, Y_{w}+\delta\right]$. In so doing, the level of tax at earnings level $Y_{w}$ is kept constant, as is $C_{w}$. This reform is illustrated by the left-hand side panel in Figure 1.

\section{INSERT FIgURE 1 ABOUt HeRE.}

The behavioral response to this reform by a worker of skill $w$ is captured by the compensated elasticity of earnings with respect to $1-T^{\prime}(Y): 11$

$$
\varepsilon_{w} \stackrel{\text { def }}{=} \frac{1-T^{\prime}\left(Y_{w}\right)}{Y_{w}} \cdot \frac{\partial Y}{\partial \tau}=\frac{\mathcal{U}_{Y}^{\prime}}{Y_{w} \cdot\left[\mathcal{U}_{Y Y}^{\prime \prime}-2\left(\frac{\mathcal{U}_{Y}^{\prime}}{\mathcal{U}_{c}^{\prime}}\right) \mathcal{U}_{C Y}^{\prime \prime}+\left(\frac{\mathcal{U}_{Y}^{\prime}}{\mathcal{U}_{c}^{\prime}}\right)^{2} \mathcal{U}_{C C}^{\prime \prime}-T^{\prime \prime}\left(Y_{w}\right) \cdot \mathcal{U}_{C}^{\prime}\right]}>0
$$

When the marginal tax rate is decreased by $\tau$, a unit rise $\Delta Y_{w}$ in earnings generates a higher gain $\Delta C_{w}=\left(1-T^{\prime}\left(Y_{w}\right)+\tau\right) \Delta Y_{w}$ of consumption. Therefore, workers substitute earnings for leisure. Finally, this reform only has a second-order effect on $U_{w}$ and thereby on the participation decisions 12

The next elementary tax reform captures the income effect around the actual tax schedule. The level of tax decreases by a small lump sum $\rho$ over a range in earnings $\left[Y_{w}-\delta, Y_{w}+\delta\right]$. This reform is illustrated by the right-hand side panel in Figure 1. Along the intensive margin, the behavioral response for a worker of skill $w$ to this reform is captured by the income effect:

$$
\eta_{w} \stackrel{\text { def }}{\equiv} \frac{\partial Y}{\partial \rho}=\frac{\left(\frac{\mathcal{U}_{Y}^{\prime}}{\mathcal{U}_{C}^{\prime}}\right) \mathcal{U}_{C C}^{\prime \prime}-\mathcal{U}_{C Y}^{\prime \prime}}{\mathcal{U}_{Y Y}^{\prime \prime}-2\left(\frac{\mathcal{U}_{Y}^{\prime}}{\mathcal{U}_{c}^{\prime}}\right) \mathcal{U}_{C Y}^{\prime \prime}+\left(\frac{\mathcal{U}_{Y}^{\prime}}{\mathcal{U}_{c}^{\prime}}\right)^{2} \mathcal{U}_{C C}^{\prime \prime}-T^{\prime \prime}\left(Y_{w}\right) \cdot \mathcal{U}_{C}^{\prime}}
$$

This term can be either positive or negative. However, when leisure is a normal good, the numerator is positive; hence, the income effect $(10)$ is negative.

The " $\rho$-reform" illustrated by the right-hand side panel in Figure 1 also induces some individuals of skill $w$ to enter the labor market. We capture this extensive response for individuals of skill $w$ with:

$$
\kappa_{w} \stackrel{\text { def }}{\equiv} \frac{1}{h(w)} \cdot \frac{\partial h(w)}{\partial \rho}=\frac{h_{U}^{\prime}(w)}{h(w)} \cdot \mathcal{U}_{C}^{\prime}=\frac{k\left(U_{w}-\mathcal{U}(b, 0, w)\right)}{K\left(U_{w}-\mathcal{U}(b, 0, w)\right)} \cdot \mathcal{U}_{C}^{\prime}>0
$$

\footnotetext{
${ }^{11}$ The elasticity $\varepsilon_{w}$ is compensated in the sense that the tax level is unchanged at earnings level $Y_{w}$.

${ }^{12}$ Decreasing $T^{\prime}($.$) by \tau$ implies a rise $\Delta Y_{w}$ of earnings, which itself increases $C_{w}$ by $\Delta C_{w}=$ $\left(1-T^{\prime}\left(Y_{w}\right)+\tau\right) \Delta Y_{w}$. Therefore the impact on $U_{w}$ is given by $\Delta U_{w}=\Delta \mathcal{U}\left(C_{w}, Y_{w}, w\right)=$ $\left[\left(1-T^{\prime}\left(Y_{w}\right)+\tau\right) \mathcal{U}_{C}^{\prime}+\mathcal{U}_{Y}^{\prime}\right] \Delta Y_{w}=\mathcal{U}_{C}^{\prime} \cdot\left(\varepsilon_{w} Y_{w} /\left(1-T^{\prime}\left(Y_{w}\right)\right)\right) \tau^{2}$ where the second equality follows $[5]$ and 9 ) through $\Delta Y_{w}=\left(\varepsilon_{w} Y_{w} /\left(1-T^{\prime}\left(Y_{w}\right)\right)\right) \tau$.
} 
which stands for the percentage of variation in the mass of workers with skill level $w$. Finally, we measure the elasticity of participation when, combined with a uniform decrease in the tax level by $\rho$, the welfare benefit $b$ rises by $\rho$ (i.e., when $T(Y)+b$ is kept constant). This reform captures income effects along the extensive margin. The (endogenous) semi-elasticity of the number of employed individuals of skill $w$ with respect to such a reform equals:

$$
\nu_{w} \stackrel{\text { def }}{\equiv} \kappa_{w}+\frac{h_{b}^{\prime}(w)}{h(w)}=\frac{k\left(U_{w}-\mathcal{U}(b, 0, w)\right)}{K\left(U_{w}-\mathcal{U}(b, 0, w)\right)} \cdot\left[\mathcal{U}_{C}^{\prime}\left(C_{w}, Y_{w}, w\right)-\mathcal{U}_{C}^{\prime}(b, 0, w)\right]
$$

When the utility function $\mathcal{U}(., .,$.$) is additively separable and concave in consumption and if$ $C_{w}>b, \mathcal{U}_{C}^{\prime}\left(C_{w}, Y_{w}, w\right)$ is lower than $\mathcal{U}_{C}^{\prime}(b, 0, w)$. Income effects along the extensive margin are then negative, which corresponds to the "normal" case.

The behavioral responses given in (7), (9), 10), 111) and (12) are endogenous in that they depend on the skill level $w$, the earnings level $Y$ and the tax function $T($.$) . In particular, the$ various responses along the intensive margin given in (7), (9) and (10) are standard (see, e.g., Saez (2001)), except for the presence of $T^{\prime \prime}($.$) in the denominators. An exogenous increase in$ either $w, \tau$, or $\rho$ induces a direct change in earnings $\Delta_{1} Y_{w}$. However, this change in turn modifies the marginal tax rate by $\Delta_{1} T^{\prime}=T^{\prime \prime}\left(Y_{w}\right) \times \Delta_{1} Y_{w}$, thereby inducing a further change in earnings $\Delta_{2} Y_{w}$. Therefore, a "circular process" takes place: the earnings level determines the marginal tax rate through the tax function, and the marginal tax rate affects the earnings level through the substitution effect. The term $T^{\prime \prime}\left(Y_{w}\right) \cdot \mathcal{U}_{C}^{\prime}$ captures the indirect effects due to this circular process (in the words of Saez (2001), see also Saez (2003, p. 483) and Appendix A). Unlike Saez (2001), we do not define the behavioral responses along a hypothetical linear tax function, but along the actual (or later optimal) tax schedule, which we allow to be nonlinear ${ }^{13}$ Therefore, our behavioral response parameters (7), (9) and (10) take into account the circular process and exhibit the term $T^{\prime \prime}($.$) in their denominators.$

\section{II.3 The government}

The government's budget constraint takes the form:

$$
b=\int_{w_{0}}^{w_{1}}\left(T\left(Y_{w}\right)+b\right) \cdot h(w) \cdot d w-E
$$

where $E$ is an exogenous amount of public expenditures. For each additional worker of skill $w$, the government collects taxes $T\left(Y_{w}\right)$ and saves welfare benefit $b$.

Turning now to the government's objective, we adopt a welfarist criterion that sums over all types of individuals a transformation $G(v, w, \chi)$ of individuals' utility $v$, with $G(., .,$.$) twice-$ continuously differentiable and $G_{v}^{\prime}>0$. Given the labor supply decisions, the government's

\footnotetext{
${ }^{13}$ See also Blomquist and Simula (2010) who calculate the marginal deadweight loss when the income tax is nonlinear.
} 
objective is:

$$
\begin{aligned}
\Omega= & \int_{w_{0}}^{w_{1}}\left\{\int_{-\infty}^{U_{w}-\mathcal{U}(b, 0, w)} G\left(U_{w}-\chi, w, \chi\right) \cdot k(\chi, w) d \chi\right. \\
& \left.+\int_{U_{w}-\mathcal{U}(b, 0, w)}^{\chi_{\max }} G(\mathcal{U}(b, 0, w), w, \chi) \cdot k(\chi, w) d \chi\right\} f(w) d w
\end{aligned}
$$

The social transformation function $G(., .,$.$) depends not only on the utility levels v$ of individuals, but also on their exogenous type $(w, \chi)$. Our social welfare function generalizes the BergsonSamuelson social objective, which does not depend on the individuals' type. With the latter criterion, the preferences for redistribution would be induced by the concavity of $G($.$) ; that$ is, by $G_{v v}^{\prime \prime}<0$. Our specification also encompasses the case where function $G(., .,$.$) equals a$ type-specific exogenous weight times the individuals' level of utility. The government's desire to compensate for heterogeneous skill endowments would then require $G_{v w}^{\prime \prime}<0$.

Let $\lambda$ denote the marginal social cost of public funds $E$. For a given tax function $T($.$) , we$ denote $g_{w}$ (respectively $g_{0}$ ) the (average and endogenous) marginal social weight associated with employed individuals of skill $w$ (with the nonemployed), expressed in terms of public funds by:

$$
\begin{aligned}
& g_{w} \stackrel{\text { def }}{\equiv} \mathbb{E}_{\chi}\left[\frac{G_{v}^{\prime}\left(U_{w}-\chi, w, \chi\right) \cdot \mathcal{U}_{C}^{\prime}\left(C_{w}, Y_{w}, w\right)}{\lambda} \mid w, \chi \leq U_{w}-\mathcal{U}(b, 0, w)\right] \\
& g_{0} \stackrel{\text { def }}{\equiv} \mathbb{E}_{w, \chi}\left[\frac{G_{v}^{\prime}(\mathcal{U}(b, 0, w), w, \chi) \cdot \mathcal{U}_{C}^{\prime}(b, 0, w)}{\lambda} \mid \chi>U_{w}-\mathcal{U}(b, 0, w)\right]
\end{aligned}
$$

The government values an additional dollar to the $h(w)$ employed individuals of skill $w$ (to the $1-H\left(w_{1}\right)$ nonemployed) as $g_{w}$ times $h(w)$ dollars ( $g_{0}$ times $1-H\left(w_{1}\right)$ dollars). The government thus wishes to transfer income from individuals whose social weight is below 1 to those whose social weight is above 1 . As will be made clear below, $g_{0}$ and the shape of the marginal social weights $w \mapsto g_{w}$ entirely summarize how the government's preferences influence the optimal tax policy. The only properties we have are that $g_{0}$ and $g_{w}$ are positive. In particular, the shape of $w \mapsto g_{w}$ can be non-monotonic, decreasing or increasing and we can have $g_{0}$ above or below $g_{w_{0}}$. However, a government that has a redistributive motive would typically adopt a decreasing shape $w \mapsto g_{w}$ of social welfare weights, as discussed in Section IV.

\section{Optimal marginal tax rates}

\section{III.1 Derivation of the optimal marginal tax formula}

The government's problem consists in finding a nonlinear income tax schedule $T($.$) and a welfare$ benefit $b$ to maximize the social objective (14), subject to the budget constraint (13) and the labor supply decisions along both margins. In this section, we directly derive the optimal tax formula through small perturbations of the optimal tax function. Following Mirrlees (1971), 
Appendix B solves the government's problem in terms of incentive-compatible allocations, using optimal control techniques and verifies that both methods lead to the same optimal tax formulae.

Proposition 1 The optimal tax policy must verify

$$
\begin{gathered}
\frac{T^{\prime}\left(Y_{w}\right)}{1-T^{\prime}\left(Y_{w}\right)}=\mathcal{A}(w) \cdot \mathcal{B}(w) \cdot \mathcal{C}(w) \\
0=\mathcal{C}\left(w_{0}\right) \\
1-g_{0}\left(1-\int_{w_{0}}^{w_{1}} h(n) \cdot d n\right)-\int_{w_{0}}^{w_{1}} g_{n} \cdot h(n) \cdot d n= \\
\int_{w_{0}}^{w_{1}}\left\{\eta_{n} \cdot T^{\prime}\left(Y_{n}\right)+\nu_{n} \cdot\left(T\left(Y_{n}\right)+b\right)\right\} \cdot h(n) \cdot d n
\end{gathered}
$$

where

$$
\begin{aligned}
\mathcal{A}(w) \stackrel{\text { def }}{\equiv} & \frac{\alpha_{w}}{\varepsilon_{w}} \quad \mathcal{B}(w) \stackrel{\text { def }}{\equiv} \frac{H\left(w_{1}\right)-H(w)}{w \cdot h(w)} \\
\mathcal{C}(w) \stackrel{\text { def }}{\equiv} & \frac{\int_{w}^{w_{1}}\left\{1-g_{n}-\eta_{n} \cdot T^{\prime}\left(Y_{n}\right)-\kappa_{n}\left(T\left(Y_{n}\right)+b\right)\right\} \cdot h(n) \cdot d n}{H\left(w_{1}\right)-H(w)}
\end{aligned}
$$

Equation (17) summarizes the trade-off underlying the choice of the marginal tax rate at earnings level $Y_{w}$. We consider the effects of an infinitesimal perturbation of the tax function as depicted in the left hand-side panel of Figure 2. Marginal tax rates are uniformly decreased by an amount $\tau$ over a range of earnings $\left[Y_{w}-\delta, Y_{w}\right]$. Therefore, the tax levels uniformly decrease by an amount $\rho=\tau \times \delta$ for all skill levels $n$ above $w$. This tax reform has four (first-order) effects: a substitution effect for taxpayers whose earnings before the reform are in $\left[Y_{w}-\delta, Y_{w}\right]$, and some mechanical, income and participation effects for taxpayers with skill $n$ above $w$.

\section{INSERT Figure 2 ABOUt HeRE.}

Substitution effect The substitution effect takes place on the range of gross earnings $\left[Y_{w}-\delta, Y_{w}\right]$. The mass of workers affected by the substitution effect is $\hat{h}\left(Y_{w}\right) \cdot \delta$. For these workers, according to Equation (9), the decrease by $\tau$ of the marginal tax rate induces a rise $\Delta Y_{w}$ of their earnings, with

$$
\Delta Y_{w}=\frac{\varepsilon_{w} \cdot Y_{w}}{1-T^{\prime}\left(Y_{w}\right)} \cdot \tau
$$

The tax reform has only a second-order effect on $U_{w}$ and thereby on the participation decision and its contribution to the government objective. However, the rise in earnings increases the government's tax receipt by $T^{\prime}\left(Y_{w}\right) \cdot \Delta Y_{w}$. Hence, given that $\tau \times \delta=\rho$, the total substitution effect equals:

$$
\mathcal{S}_{w}=\frac{T^{\prime}\left(Y_{w}\right)}{1-T^{\prime}\left(Y_{w}\right)} \cdot \varepsilon_{w} \cdot Y_{w} \cdot \hat{h}\left(Y_{w}\right) \cdot \rho
$$

Workers of skill $n$ above $w$ face a reduction $\rho$ in their tax level with no change in the marginal tax rate. This has three consequences. 
Mechanical effects First, in the absence of any behavioral response from these workers, the government gets $\rho$ units of tax receipts less from each of the $h(n)$ workers of skill $n$. However, the tax reduction induces a higher consumption level $C_{n}$, which is valued $g_{n}$ by the government. Hence the total mechanical effect at skill $w$ is:

$$
\mathcal{M}_{w}=-\int_{w}^{w_{1}}\left(1-g_{n}\right) \cdot h(n) \cdot d n \cdot \rho
$$

Income effects Second, the tax reduction induces each of the workers of skill $n$ to change her intensive choice by $\Delta Y_{n}=\eta_{n} \cdot \rho$ (see Equation (10p). This income response has only a firstorder effect on the government's budget: each of the $h(n)$ workers of skill $n$ pays $T^{\prime}\left(Y_{n}\right) \cdot \Delta Y_{n}$ additional tax. Hence, the total income effect at skill $n$ equals:

$$
\mathcal{I}_{w}=\int_{w}^{w_{1}} \eta_{n} \cdot T^{\prime}\left(Y_{n}\right) \cdot h(n) \cdot d n \cdot \rho
$$

Participation effects Finally, the reduction in tax levels induces $\kappa_{n} \cdot h(n) \cdot \rho$ individuals of skill $n$ to enter employment (see Equation (11)). The change in participation decisions then has only a first-order effect on the government's budget. Each additional worker of skill $n$ pays $T(n)$ taxes, and the government saves the welfare benefit $b$. Hence, the total participation effect at skill $w$ equals:

$$
\mathcal{P}_{w}=\int_{w}^{w_{1}} \kappa_{n} \cdot\left(T\left(Y_{n}\right)+b\right) \cdot h(n) \cdot d n \cdot \rho
$$

The sum of $\mathcal{S}_{w}, \mathcal{M}_{w}, \mathcal{I}_{w}$ and $\mathcal{P}_{w}$ should be zero if the original tax function is optimal. Rearranging terms then gives:

$$
\frac{T^{\prime}\left(Y_{w}\right)}{1-T^{\prime}\left(Y_{w}\right)}=\frac{1}{\varepsilon_{w}} \times \frac{\int_{w}^{w_{1}}\left\{1-g_{n}-\eta_{n} \cdot T^{\prime}\left(Y_{n}\right)-\kappa_{n}\left(T\left(Y_{n}\right)+b\right)\right\} \cdot h(n) \cdot d n}{Y_{w} \cdot \hat{h}\left(Y_{w}\right)}
$$

which gives (17) because of (8).

Equation (18) describes the effects of providing a uniform transfer $\rho$ to all employed individuals. This tax perturbation does not affect marginal tax rates, so it only induces the mechanical, income and participation effects. The sum of (21), (22) and (23) evaluated for $w=w_{0}$ should be nil at the optimum, which leads to $(18)$. Equations $(17)$ and $(18)$ imply that the optimal marginal tax rate is nil at the minimum earnings level 14

To grasp the intuition behind Equation 19 , consider a increase by $\rho$ in welfare benefit $b$ and a unit lump-sum decrease by $\rho$ in the tax function for all skill levels. This reform changes neither the marginal nor the participation tax rates. Hence, it has only mechanical and income

\footnotetext{
${ }^{14}$ Intuitively, increasing the marginal tax rate at a skill level $w^{\prime}$ improves equity when the extra tax revenue can be redistributed towards a positive mass of people with skill levels less than or equal to $w^{\prime}$. Given that the mass of agents with a skill level less than or equal to $w_{0}$ is nil, a positive marginal tax rate at $w_{0}$ does not improve equity. It does, however, distort the labor supply. The optimal marginal tax rate at the lowest skill level then equals zero. This result no longer holds if there is bunching at the bottom of skill distribution (Seade (1977)).
} 
effects along the intensive and extensive margins. This reform induces a (mechanical) loss of the tax revenues valued 1 by the government and a gain in the social objective. The latter amounts to $g_{0} \cdot\left(1-\int_{w_{0}}^{w_{1}} h(n) \cdot d n\right) \cdot \rho$ for the nonemployed and $\int_{w_{0}}^{w_{1}} g_{n} \cdot h(n) \cdot d n \cdot \rho$ for workers. Therefore, the mechanical effect corresponds to the left-hand side of 19 . The right-hand side captures the income effects along both margins 15 First, through the income response along the intensive margin, earnings change by $\Delta Y_{n}=\eta_{n} \cdot \rho$. This affects tax revenues by the weighted integral of $\Delta Y_{n} \cdot T^{\prime}\left(Y_{n}\right)=\eta_{n} \cdot T^{\prime}\left(Y_{n}\right) \cdot \rho$. Second, participation decisions change through the income effect by $\Delta h(n)=\nu_{n} \cdot h(n) \cdot \rho$ (See Equation (12)). Given that for each additional worker of skill $n$, tax revenues increase by $T\left(Y_{n}\right)+b$, the total impact is the weighted integral of $\nu_{n} \cdot\left(T\left(Y_{n}\right)+b\right) \cdot \rho$. In the normal case, $\eta_{n}<0$ and $\nu_{n}<0$. Therefore, as $T\left(Y_{n}\right)+b$ is typically positive for most workers, we expect that larger income effects along both margins increase the average of the social welfare weights $\left(g_{0}\right.$ and $g_{n}$ 's) above 1.

\section{III.2 Comparison with the optimal tax literature}

Equation (17) decomposes the determinants of the optimal marginal tax rates into three components. $\mathcal{A}(w)$ is the efficiency term. $\mathcal{B}(w)$ captures the role of the skill distribution among employed individuals. Finally, $\mathcal{C}(w)$ stands for the social preferences for income redistribution, taking into account the induced responses through income effects and along the participation margin.

There are two apparent differences between our formulation of the efficiency term $\mathcal{A}(w)$ and that in the literature. The first is the presence of $T^{\prime \prime}\left(Y_{w}\right)$ in the definitions (7) and (9) of $\alpha_{w}$ and $\varepsilon_{w}$. This is because of our definitions of behavioral responses along a potentially nonlinear income tax schedule and the induced endogeneity of marginal tax rates. However, in the ratio $\alpha_{w} / \varepsilon_{w}$, these additional terms cancel out. Consequently, the term $\mathcal{A}(w)$ is the same whether we define behavioral elasticities $\alpha_{w}$ and $\varepsilon_{w}$ along the optimal tax schedule (as in the present study) or along a "virtual" linear tax schedule (as common in the literature; see, e.g., Piketty (1997), Diamond (1998) and Saez (2001)). The second difference is induced by our assumption on preferences (1). The literature typically imposes that preferences over consumption and inwork effort do not vary with the skill level, and are described by $\mathfrak{U}(C, Y / w)$. Then, it happens that the numerator of $\mathcal{A}(w)$ coincides with one plus the uncompensated elasticity of the labor supply. This is counterintuitive, as it suggests that ceteris paribus marginal tax rates increase with the latter elasticity. Our more general assumption on preferences enables us to stress that what matters is the elasticity $\alpha_{w}$ of earnings with respect to the skill level. Marginal tax rates are inversely related to the compensated elasticity $\varepsilon_{w}$, in the vein of the Ramsey's "inverse

\footnotetext{
${ }^{15}$ Diamond (1975), Sandmo (1998) and Jacobs (2010) emphasize that the social value of public funds should only take into account the behavioral responses from the income effects. Equation 190 shows that only income effects along the intensive $\eta_{w}$ and extensive $\nu_{w}$ margins matter.
} 
elasticity"rule.

The term $\mathcal{B}(w)$ captures the role of the skill distribution. Consider an increase in the marginal tax rate around the earnings level $Y_{w}$ (the left hand-side of Figure 2). The induced distortions along the intensive margin is proportional to the product of the skill level $w$ times the number of workers at that skill level, $w \cdot h(w)$ (Atkinson (1990)). However, the gain in tax revenues is proportional to the number $H\left(w_{1}\right)-H(w)$ of employed individuals of skill $n$ above $w$. Two differences with the literature are worth noting. First, because of the extensive margin responses, what matters is the distribution of skills among employed individuals, instead of the one over the entire population. Given that $h(w) / f(w)$ equals the employment rate of workers of skill $w$ and $\left(H\left(w_{1}\right)-H(w)\right) /(1-F(w))$ equals the aggregate employment rate above skill $w$, one can further decompose $\mathcal{B}(w)$ into its exogenous and endogenous components:

$$
\mathcal{B}(w)=\frac{1-F(w)}{w \cdot f(w)} \cdot \frac{\frac{H\left(w_{1}\right)-H(w)}{1-F(w)}}{\frac{h(w)}{f(w)}}
$$

The first term on the right-hand side equals the exogenous skill distribution term of Diamond (1998). ${ }^{16}$ Second, the distribution term in (Saez (2001), Equation (19)) concerns the virtual distribution of earnings and not the skill distribution. This is how Saez (2001) removes the counterintuitive presence of the uncompensated labor supply elasticity in the numerator of his efficiency term. Using $\sqrt{8}$, one then obtains that $\alpha_{w} \mathcal{B}(w)=\left(\hat{H}\left(Y_{w_{1}}\right)-\hat{H}\left(Y_{w}\right)\right) /\left(Y_{w} \cdot \hat{h}\left(Y_{w}\right)\right)$, so our optimal tax formula can also be expressed in terms of the earnings distribution, as in (24). Both formulations have their advantage. The earnings distribution has the advantage that earnings are directly observable. However, earnings are endogenous, and hence the observed and optimal earnings distributions may differ. To compute optimal tax rates, one then has to specify the utility function. Once this is done, the individual's first-order condition (5) enables us to recover the individual's skill level $w$ from her observed earnings $Y$ (and from knowledge of the tax function). Accordingly, the advantage of the formulation in terms of the earnings distribution disappears. Nevertheless, we present both formulations and leave it to interested readers to choose the one they prefer.

The term $\mathcal{C}(w)$ captures the influence of social preferences for income redistribution, taking into account the induced responses through income effects and along the participation margin. $\mathcal{C}(w)$ equals the average of mechanical, income and participation effects for all workers of skill $n$ above $w$. Diamond (1998) considers the case where participation is exogenous and there is no income effect. Introducing income effects or participation responses in the analysis then amounts to modifying the social weight to:

$$
\breve{g}_{n} \stackrel{\text { def }}{=} g_{n}+\kappa_{n} \cdot\left(T\left(Y_{n}\right)+b\right)+\eta_{n} \cdot T^{\prime}\left(Y_{n}\right)
$$

\footnotetext{
${ }^{16}$ Diamond's $(1998) \mathcal{C}(w)$ corresponds to our $\mathcal{B}(w)$ and vice versa.
} 
Saez (2002, p. 1055) has explained why the government is more willing to transfer income to groups of employed individuals for which the participation response $\kappa_{n}$ or the participation tax $T\left(Y_{n}\right)+b$ is larger. The behavioral parameter $\kappa_{n}$ is positive, so a decrease in the level of tax paid by workers of skill $n$ induces more of them to work. Whenever the participation tax $T\left(Y_{n}\right)+b$ is positive, tax revenues increase, which is beneficial to the social planner. A similar interpretation can be made for the income effect. Typically, leisure is a normal good (hence $\eta_{n}<0$ ). Then, through the income effect, a decrease in the level of tax paid by workers of skill $n$ induces them to work less through the income effect. Whenever workers face a positive marginal tax rate, this response decreases the tax they pay, which is detrimental to the government. Therefore, the government is more willing to transfer income to groups of employed individuals with either lower income effects (i.e. higher $\eta_{n}$ ) or lower marginal tax rates (Saez (2001)).

\section{Properties of the second-best optimum}

\section{IV.1 Sufficient condition for nonnegative marginal tax rates}

We first consider the special case where the labor supply decisions take place only along the extensive margin, as assumed in Diamond (1980) and Choné and Laroque (2005, 2009a), so $\varepsilon_{w}=\eta_{w}=0$. The optimal tax formula then verifies $[17$

$$
T\left(Y_{w}\right)=\frac{1-g_{w}}{\kappa_{w}}-b
$$

The optimal level of tax then trades off the mechanical effect (captured by the social weight $g_{w}$ ) and the participation response effect (captured by the participation response $\kappa_{w}$ ) of a rise in the level of tax. Marginal tax rates are then everywhere nonnegative if along the optimal allocation, the function $Y \mapsto\left(1-g_{w}\right) / \kappa_{w}$ is increasing. The following Proposition shows that this result remains valid in the presence of responses along the intensive margin.

Proposition 2 If along the optimal allocation, $w \mapsto \frac{1-g_{w}}{\kappa_{w}}$ is increasing, marginal tax rates are always nonnegative. Furthermore, they are almost everywhere positive, except at the two extremities $Y_{w_{0}}$ and $Y_{w_{1}}$.

This Proposition is proved in Appendix C. The intuition is illustrated in the right hand-side panel of Figure 2. This figure depicts the level of the participation tax $T\left(Y_{w}\right)+b$ paid by a worker of skill $w$, as a function of her skill level. When labor supply responses are only along the extensive margin, the optimal tax schedule is represented by the dashed curve. This corresponds to the optimal trade-off between the mechanical and participation effects. If $w \mapsto\left(1-g_{w}\right) / \kappa_{w}$

\footnotetext{
${ }^{17}$ In the absence of a response along the intensive margin, substitution effects $\mathcal{S}_{w}$ in 20 and income effects $\mathcal{I}_{w}$ in 22 are nil at each skill level. Therefore, the sums of the mechanical $\mathcal{M}_{w}$ and the participation $\mathcal{P}_{w}$ effects must be nil at each skill level, which gives 25 .
} 
is increasing in $w$, this function is increasing in the skill level. However, when workers can also decide along their intensive margin, the increasing tax function and its positive marginal tax rates induce distortions of the intensive choices. Hence, the optimal tax function depicted by the solid curve is flatter than the optimal curve without an intensive margin to limit the distortions along the intensive margin. It also has to be as close as possible to the optimal curve without intensive margin to limit the departures from the optimal trade-off between the participation and mechanical effects.

Proposition 3 If along the optimal allocation, $w \mapsto \frac{1-g_{w}}{\kappa_{w}}$ is increasing and if $g_{w_{0}} \leq 1$ for all skill levels, then the in-work benefits (if any) are smaller than the welfare benefit $b$.

This Proposition is proved in Appendix D. The assumption that $g_{w} \leq 1$ for all skills is restrictive as it implies that in the case without intensive responses, the optimal tax is characterized by providing the least-skilled workers with a lower benefit than the nonemployed (hence, a Negative Income Tax is optimal). This result remains valid in the presence of intensive responses as the optimal tax function under unobserved skills is flatter than that under observed skills. Proposition 3 emphasizes this result.

In the absence of behavioral responses along the intensive margin, in-work benefits for the working poor (of skill $w_{0}$ ) are larger than the welfare benefits if and only if $g_{w_{0}}>1$. By continuity, as long as the compensated elasticity (along the intensive margin) $\varepsilon_{w_{0}}$ is sufficiently small, in-work benefits should remain higher than welfare benefits; hence, an EITC is optimal, as already stressed by Saez (2002).

In sum, according to Proposition 2 (Proposition 3 ) the restrictions on primitives that ensures positive marginal (marginal and participation) tax rates in the model with extensive margin only also guarantee positive marginal (marginal and participation) tax rates in the model with an intensive and an extensive margins.

\section{IV.2 Examples}

The sufficient condition in Propositions 2 and 3 depends on the patterns of social weights $g_{w}$ and extensive behavioral responses $\kappa_{w}$, both of which are endogenous. This subsection provides examples where the primitives of the model guarantee the sufficient conditions in Propositions 2 and 3 .

Our first example specifies the primitives of the model in such a way that $g_{w}$ and $\kappa_{w}$ become exogenous. For this purpose, individuals' preferences are quasilinear: $\mathcal{U}(C, Y, w)=C-\mathcal{V}(Y, w)$ with $\mathcal{V}_{Y}^{\prime}, \mathcal{V}_{Y Y}^{\prime \prime}>0>\mathcal{V}_{Y w}^{\prime \prime}$. The marginal utility of consumption $\mathcal{U}_{C}^{\prime}(C, Y, w)$ is then always equal to one. Moreover, we specify the distribution of the disutility of participation $\chi$ conditional on any skill level $w$ as $K(\chi, w)=\exp \left(a_{w}+\kappa \cdot \chi\right)$, where $a_{w}$ is a skill-specific parameter adjusted 
to keep some individuals out-of-the labor force at the optimum. Then, according to Equation (11), $\kappa_{w}$ is always equal to parameter $\kappa$ and thereby constant along the skill distribution. Finally, the social objective is linear in utility levels with skill-specific weights $\gamma_{w}$. Given that the specification of the individuals' utility rules out income effects, we have $g_{w}=\gamma_{w} / \int_{w_{0}}^{w_{1}} \gamma_{w} d w$ (see (15), (16) and (19)). Therefore, under redistributive social preferences, $w \mapsto \gamma_{w}$ is decreasing, so $\left(1-g_{w}\right) / \kappa_{w}$ is decreasing. The marginal tax rates are then nonnegative according to Proposition 2. Note that in this example, $g_{w_{0}}$ is necessarily strictly greater than one, so the optimal participation tax may be negative at the bottom. A negative participation tax at the bottom is nevertheless consistent with nonnegative marginal tax rates over the entire income distribution as we assume a positive lower bound for the skill distribution. Hence, the lowest earnings level is positive and the tax function can jump between $Y=0$ and $Y_{w_{0}}$.

This first example is very specific. In general, we consider that it is plausible that $w \mapsto 1-g_{w}$ is nonincreasing and $w \mapsto \kappa_{w}$ is strictly decreasing. First, a redistributive government typically places a higher social welfare weight on the consumption of the least-skilled workers. Second, there is some empirical evidence that the elasticity of participation, which equals $\left(Y_{w}-T\left(Y_{w}\right)-b\right) \kappa_{w}$, is typically a nonincreasing function (see, e.g., Juhn et alii (1991), Immervoll et alii (2007) or Meghir and Phillips (2008)). Given that consumption $Y_{w}-T\left(Y_{w}\right)$ is an increasing function, one could expect $\kappa_{w}$ to decrease along the skill distribution.

We now provide more general specifications of the primitives where $w \mapsto 1-g_{w}$ is nonincreasing and $w \mapsto \kappa_{w}$ is strictly decreasing. Assume that the utility function is additively separable, i.e.:

$$
\mathcal{U}(C, Y, w)=u(C)-\mathcal{V}(Y, w)
$$

with $u_{C}^{\prime}, \mathcal{V}_{Y}^{\prime}, \mathcal{V}_{Y Y}^{\prime \prime}>0>u_{C C}^{\prime \prime}, \mathcal{V}_{Y w}^{\prime \prime}$. The additive separability restriction is only made for technical convenience. However, showing within the pure intensive model that marginal tax rates are positive without imposing the additive separability assumption (26) was a real issue (see, e.g., Sadka 1976, Seade 1982, Werning 2000). We add another restriction on preferences. For an employed individual, the more skilled the worker, the lower the effort to obtain a given earnings level. However, for the nonemployed, no effort is supplied. Hence, a larger skill does not improve utility. We therefore assume:

$$
\mathcal{V}_{w}^{\prime}(Y, w) \stackrel{<}{=} \text { if } \quad \stackrel{>}{=} 0
$$

As a result, the skill-specific threshold $U_{w}-\mathcal{U}(b, 0, w)$ of $\chi$ above which an individual of type $(w, \chi)$ chooses not to participate is an increasing function of the skill level (See Equation (31) in Appendix B. The following properties are shown in Appendix E.

Property 1 If $K(\chi, w)$ is strictly log-concave with respect to $\chi$, if $w \mapsto k(\chi, w) / K(\chi, w)$ is nonincreasing in $w$ and if (26)-(27) hold, then the function $w \mapsto \kappa_{w}$ is strictly decreasing. 
The log-concavity of $K(., w)$ is a property verified by many distributions commonly used. It is equivalent to assuming that $k(\chi, w) / K(\chi, w)$ is decreasing in $\chi$. That $k(\chi, w) / K(\chi, w)$ is nonincreasing in $w$ encompasses the benchmark case where $w$ and $\chi$ are independently distributed.

Property 2 Under either Maximin or Benthamite social preferences and 201-27), the function $w \mapsto g_{w}$ is nonincreasing

Maximin (i.e., maximizing $\mathcal{U}(b, 0, w))$ and Benthamite (i.e., $G\left(U_{w}-\chi, w, \chi\right) \equiv U_{w}-\chi$ ) social preferences are polar specifications. Combining Properties 1 and 2 , the relation $w \mapsto$ $\left(1-g_{w}\right) / \kappa_{w}$ can be decreasing only if $g_{w}$ is higher than 1 . Such configuration can only occur at the bottom end of the skill distribution and is ruled out under Maximin social preferences. If instead $g_{w_{0}} \leq 1, w \mapsto\left(1-g_{w}\right) / \kappa_{w}$ is increasing, so the sufficient condition for positive marginal tax rates given in Proposition 2 holds. Therefore, Propositions 2 and 3 hold under the joint following assumptions: Maximin social objective, the utility functions verifies (26) and (27), $K(\chi, w)$ is strictly log-concave with respect to $\chi$ and $k(\chi, w) / K(\chi, w)$ is nonincreasing in $w$. Moreover, if the government is instead Benthamite and if $g_{w_{0}} \leq 1$, then Propositions 2 and 3 are again ensured.

\section{Numerical simulations for the U.S.}

This section implements our optimal tax formula on U.S data. This exercise allows us to check whether our sufficient condition for nonnegative marginal tax rates is empirically reasonable. It also highlights the quantitative impact of the extensive margin on the optimal marginal and participation tax rates.

\section{V.1 Calibration}

To calibrate the model, we need to specify social and individual preferences and the distribution of characteristics $(w, \chi)$. We consider Benthamite and Maximin social preferences. We select a specification of individual preferences that enables us to control behavioral responses along the intensive margin. Following Diamond (1998) and Saez (2002), we assume away income effects along the intensive margin (hence $\eta_{w} \equiv 0$ ) and assume the compensated elasticities to be constantly equal to $\varepsilon$ along a linear tax schedule. Moreover, individuals' preferences are concave such that a Benthamite government prefers to transfer income from high- to low- income earners. Hence, we specify:

$$
\mathcal{U}(C, Y, w)=\frac{\left(C-\left(\frac{Y}{w}\right)^{1+\frac{1}{\varepsilon}}+1\right)^{1-\sigma}}{1-\sigma}
$$


The parameter $\varepsilon$ corresponds to the compensated elasticity of earnings with respect to one minus the marginal tax rate along a linear tax schedule (see Equation (9)), while parameter $\sigma$ drives the redistributive preferences of a Benthamite government. Saez et alii (2010) survey the recent literature estimating the elasticity of earnings to one minus the marginal tax rate. They conclude that "the best available estimates range from 0.12 to 0.4 " in the U.S. We take a central value of $\varepsilon=0.25$ for our benchmark. For the concavity of preferences, we take $\sigma=0.8$ in the benchmark case. We conduct a sensitivity analysis with respect to both of these parameters.

To calibrate the skill distribution, we employ the earnings distribution in the Current Population Survey (CPS) for May 2007 ${ }^{18}$ We use the first-order condition (5) of the intensive program to infer the skill level from each observation of earnings. We consider only single individuals to avoid the complexity of interrelated labor supply decisions within families. Using the OECD tax database, the real tax schedule of singles without dependent children is well approximated by a linear tax function at rate $27.9 \%$ with an intercept of $-\$ 4,024.9$ on an annual basis. We use a quadratic kernel with a bandwidth of $\$ 3,822$ to smooth $h(w)$. High-income earners are underrepresented in the CPS. Diamond (1998) and Saez (2001) argue that the skill distribution actually exhibits a fat upper tail in the U.S., which has dramatic consequences on the shape of optimal marginal tax rates. We therefore expand (in a continuously differentiable way) our kernel estimation by taking a Pareto distribution, with an index ${ }^{19} a=2$ for skill levels between $w=\$ 20,374$ and $w_{1}=\$ 40,748$. This represents only the top $3.1 \%$ of our approximation of the skill distribution. The lower bound of the skill distribution is $w_{0}=\$ 202$. Figure 3 depicts the calibrated density distribution $f(w)$ in solid line. The dashed line is the smoothed density distribution using the quadratic kernel and the solid line is the smoothed density after expansion by the Pareto distribution.

\section{INSERT Figure 3 ABOUt HeRE.}

One needs to calibrate the conditional distribution of $\chi$. Because the participation decision is dichotomous, we must specify a functional form. We choose a logistic and skill-specific specification:

$$
K(\chi, w)=\frac{\exp \left(-a_{w}+\beta_{w} \chi\right)}{1+\exp \left(-a_{w}+\beta_{w} \chi\right)}
$$

which ensures that skill-specific employment rates are always between 0 and 1 . Parameters $a_{w}$ and $\beta_{w}$ are calibrated to obtain empirically plausible skill-specific employment rates, denoted by $L_{w}$, and elasticities of employment rates with respect to the difference in disposable incomes $C_{w}-b$, denoted by $\pi_{w}=\left(C_{w}-b\right) \kappa_{w}$. We take:

$$
L_{w}=0.7+0.1\left(\frac{w-w_{0}}{w_{1}-w_{0}}\right)^{1 / 3} \quad \pi_{w}=\pi_{0}-\pi_{1}\left(\frac{w-w_{0}}{w_{1}-w_{0}}\right) \text { with } \pi_{0}=0.5 \text { and } \pi_{1}=0.1
$$

\footnotetext{
${ }^{18}$ We multiply by 52 the weekly earnings given by the CPS survey.

${ }^{19}$ An (untruncated) Pareto distribution with Pareto index $a>1$ is such that $\operatorname{Pr}(w>\widehat{w})=C / \widehat{w}^{a}$ with $a, C \in \mathbb{R}_{0}^{+}$.
} 
These specifications are consistent with the empirical evidence that the employment rate $L_{w}$ is higher for the highly skilled. The average employment rate in the current economy equals $75.3 \%$. The elasticity $\pi_{w}$ is equal to 0.45 on average. Unreported simulations indicate that the properties of the optimal tax schedule are robust with respect to changes in the $w \mapsto L_{w}$ and $w \mapsto \pi_{w}$ relationship.

To fix the value of $b$ in the current economy, we consider the net replacement ratio of a long-term unemployed paid $67 \%$ of the average wage before entering unemployment. As this ratio is $9 \%$ in 2007 according to the OECD tax-benefit calculator ${ }^{20}$ we set $b=\$ 2,381$. Given this calibration of the current economy, we find that the budget constraint (13) is verified only when we set the exogenous revenue requirement to $E=\$ 6,110$ per capita.

\section{V.2 Benchmark simulations}

Figure 4 plots the optimal marginal tax rates (Panel (a)) and participation tax levels (Panel (b)) as functions of earnings, under the Benthamite (solid line) and Maximin (dashed line) criteria. We focus on annual earnings below $\$ 100,00021$

\section{INSERT Figure 4 ABOUt HeRE.}

\section{U-shape and positive marginal tax rates}

Panel (a) shows that the marginal tax rates follow the usual U-shaped profile obtained without extensive margin (Saez (2001), Salanié (2003)), under both criteria. All our various sensitivity analyses point out that the U-shape profile is valid. Remarkably, however, our optimal marginal tax rates are much lower than those found, without extensive margin, by Saez (2001). Section V.3 will study the quantitative importance of the extensive margin. Under Maximin, the marginal tax rates are higher than under the Benthamite criterion, except at the bottom end (for $Y$ lower than $Y=\$ 5,900$ ).

Consistent with Proposition 2, the marginal tax rates are positive under both criteria in Panel (a). Moreover, there is no distortion at the lower end of the earnings distribution whose value is $Y_{w_{0}}=\$ 508$. Under Maximin, the latter result contrasts with the optimal positive marginal tax rate in a model with intensive margin only (Boadway and Jacquet (2008)). In their paper, the social objective values only the utility of employed individuals at $Y=Y_{w_{0}}$, which explains why they do not get the no-distortion result at the bottom. Conversely, when both extensive and intensive margins are modeled, the Maximin objective values only the utility of the nonemployed. Panel (a) also illustrates that the absence of distortion at the bottom is

\footnotetext{
${ }^{20}$ See http://www.oecd.org/document/18/0,3343,en_2649_34637_39717906_1_1_1_1,00.html

${ }^{21}$ Income earners above $\$ 100,000$ represent $3.73 \%$ and $5.66 \%$ of the population at the Benthamite optimum and at the Maximin optimum, respectively.
} 
a very local property: when $Y=\$ 2,150$, the marginal tax rate climbs to $60.5 \%$ (58.8\%) under Benthamite (Maximin) preferences.

\section{EITC under Bentham and NIT under Maximin}

Figure 4(b) illustrates that the participation tax levels at the bottom of the earnings distribution are typically negative under a Benthamite criterion. The optimality of a negative participation tax on the poorest workers is usually interpreted as a case for an EITC (Saez 2002). We find $b=\$ 2,665$ and $-T\left(Y_{w_{0}}\right)=\$ 9,345$. Contrastingly, Figure 4 (b) also emphasizes that the participation tax levels at the bottom of the earnings distribution are positive under Maximin. An NIT then prevails. This is a standard result of the pure extensive margin model (Choné and Laroque (2005)), which is still valid here when considering extensive and intensive margins together (Saez (2002)). Intuitively, it is hardly desirable to transfer income to the least-skilled workers, since their well-being does not matter under Maximin. At the Maximin optimum, we find $b=\$ 4,190$ and $-T\left(Y_{w_{0}}\right)=\$ 3,860$.

Figure 5(a) describes how the negative participation tax on least-skilled workers enables employment rates to be boosted well above their values in the current economy under Benthamite social preferences. Moreover, Panel (b) illustrates how these negative participation tax rates (in the Bentham economy) increase the gross utility levels $U_{w}$ of low-skilled workers significantly beyond their values in the current economy.

\section{INSERT Figure 5 ABOUt HERE.}

\section{V.3 Importance of the Extensive Margin}

This section illustrates the major role played by the extensive margin. We compare how different are the optimal tax schedules with and without taking the extensive margin into account, while the distribution of skills and the number of nonemployed are exogenously kept at their calibrated levels.

\section{INSERT Figure 6 ABOUt HERE.}

Figure 6(a) shows that canceling the extensive margin substantially increases the marginal tax rates. To quantify this change, we compute the mean of marginal tax rates between 0 and $\$ 100,000$, weighted by the density of employed workers. This mean increases by 11.3 percentage points under Bentham and by 36.5 percentage points under Maximin. This is expected from Equation (17) and the $C(w)$ term where $\kappa_{n}$ is set equal to zero. ${ }^{22}$ As expected as well, the optimal marginal tax rate at the lower bound is strictly positive (and very high) under Maximin

\footnotetext{
${ }^{22}$ Our simulations also take into account the changes in welfare weights $g_{n}$ in 17 .
} 
when the extensive margin is neglected ${ }^{23}$ Figure (6b) shows that under Benthamite preferences, the participation tax becomes positive at the bottom of the earnings distribution when the extensive margin is shut down.

\section{V.4 Sensitivity analysis}

As illustrated in Figure 7(a), a rise in the parameter $\sigma$ increases the aversion to inequality and this leads to a rise in marginal tax rates. Panel b shows that the optimal participation tax at the low end of the earnings distribution evolves ambiguously with $\sigma$. Intuitively participation taxes at the bottom are lower when the welfare weight on the least skilled workers $g_{w_{0}}$ becomes very important. However, with a very high aversion to inequality, the welfare of the nonemployed becomes dominant and $g_{w_{0}}$ decreases.

\section{INSERT Figure 7 ABOUt HeRE.}

Figure 8(a) illustrates that the marginal tax rates decrease with the elasticity of earnings $\varepsilon$, as theoretically expected from the implied decrease of $\mathcal{A}(w)$ in Equation (17). Figure 8(a) illustrates this result with $\varepsilon$ equal to 0.25 and 0.5, under Maximin and Benthamite preferences. The only exception is under Maximin for earnings below $\$ 5,249$. Figure 8 (b) emphasizes that participation taxes decrease (increase) with $\varepsilon$ for earnings above (below) roughly around $\$ 30,000$, under both criteria.

\section{INSERT FiguRE 8 ABOUT HERE.}

The following properties appear robust across these sensitivity analyses: marginal tax rates are positive and U-shaped; participation taxes are positive under Maximin; participation taxes are negative at the bottom of the earnings distribution under the Benthamite criterion; there is no bunching. Our sufficient condition for positive marginal tax rates also appears robust, except when the elasticity of earnings $\varepsilon$ is at least 0.5 . The sufficient condition is then violated over a very small interval at the bottom of the skill distribution. However, the marginal tax rates remain positive.

\section{Conclusion}

This paper explored the optimal income tax schedule when labor supply responds simultaneously along both the extensive and intensive margins. Individuals are heterogeneous across two dimensions: their skill and their disutility of participation. We derived a mild sufficient condition

\footnotetext{
${ }^{23}$ In the absence of the extensive margin, the participation tax at the bottom end is adjusted so that the welfare of the nonemployed is identical to the one of the least skilled worker. Consequently, there is a positive mass of welfare weights attached to these workers and the Boadway and Jacquet (2008)'s argument for positive marginal tax rate at the bottom applies.
} 
for nonnegative marginal tax rates over the entire skill distribution. This condition is derived using a new method to sign distortions (along the intensive margin) in screening models with random participation. Our exercise illustrated that at the optimum, negative participation tax rates can coexist with positive marginal tax rates everywhere.

Using U.S. data, we implemented our optimal tax formula. This exercise emphasized that the optimal tax schedule is U-shaped as in the literature without an extensive margin. However, introducing the extensive margin quite substantially reduces the marginal tax rates. Interestingly, the marginal tax rates are always positive in our simulations.

The work undertaken in this study identifies several possible extensions. Among them, the method to sign distortion along the intensive margin can be applied to other contexts of monopoly screening with random participation à la Rochet and Stole (2002). Moreover, we ignored the interactions in labor supply decisions within couples (Kreiner et alii (2009)). Finally, it would be interesting to extend the numerical simulations to countries other than the U.S.

\section{Appendices}

\section{A Behavioral elasticities}

We define:

$$
\begin{aligned}
& \mathcal{Y}(Y, w, \tau, \rho) \stackrel{\text { def }}{=}\left(1-T^{\prime}(Y)+\tau\right) \cdot \mathcal{U}_{C}^{\prime}\left(Y-T(Y)+\tau\left(Y-Y_{w}\right)+\rho, Y, w\right) \\
& +\mathcal{U}_{Y}^{\prime}\left(Y-T(Y)+\tau\left(Y-Y_{w}\right)+\rho, Y, w\right)
\end{aligned}
$$

The first-order condition (5) is equivalent to $\mathcal{Y}\left(Y_{w}, w, 0,0\right)=0$. When $T($.$) is twice-differentiable,$ one has (using (50):

$$
\begin{aligned}
\mathcal{Y}_{Y}^{\prime}\left(Y_{w}, w, 0,0\right) & =\mathcal{U}_{Y Y}^{\prime \prime}-2\left(\frac{\mathcal{U}_{Y}^{\prime}}{\mathcal{U}_{c}^{\prime}}\right) \mathcal{U}_{C Y}^{\prime \prime}+\left(\frac{\mathcal{U}_{Y}^{\prime}}{\mathcal{U}_{c}^{\prime}}\right)^{2} \mathcal{U}_{C C}^{\prime \prime}-T^{\prime \prime}\left(Y_{w}\right) \cdot \mathcal{U}_{C}^{\prime} \\
\mathcal{Y}_{w}^{\prime}\left(Y_{w}, w, 0,0\right) & =\frac{\mathcal{U}_{Y w}^{\prime \prime} \cdot \mathcal{U}_{C}^{\prime}-\mathcal{U}_{C w}^{\prime \prime} \cdot \mathcal{U}_{Y}^{\prime}}{\mathcal{U}_{C}^{\prime}} \\
\mathcal{Y}_{\tau}^{\prime}\left(Y_{w}, w, 0,0\right) & =\mathcal{U}_{C}^{\prime} \\
\mathcal{Y}_{\rho}^{\prime}\left(Y_{w}, w, 0,0\right) & =\frac{\mathcal{U}_{C Y}^{\prime \prime} \cdot \mathcal{U}_{C}^{\prime}-\mathcal{U}_{C C}^{\prime \prime} \cdot \mathcal{U}_{Y}^{\prime}}{\mathcal{U}_{C}^{\prime}}
\end{aligned}
$$

The second-order condition is $\mathcal{Y}_{Y}^{\prime}\left(Y_{w}, w, 0,0\right) \leq 0$, which gives (6). When this condition holds with strict inequality, and when the global maximum in $Y$ of $\mathcal{U}(Y-T(Y), Y, w)$ is unique, we can apply the implicit function theorem to $\mathcal{Y}\left(Y_{w}, w, 0,0\right)$. Provided that the sizes of the changes in $w, \tau$ and $\rho$ are small enough for the maximum of $Y \mapsto \mathcal{U}(Y-T(Y), Y, w)$ to change only marginally, one has for $x=w, \tau, \rho$, that $\partial Y / \partial x=-\mathcal{Y}_{x}^{\prime} / \mathcal{Y}_{Y}^{\prime}$ evaluated at $\left(Y_{w}, w, 0,0\right)$. This leads directly to (7), (9) and (10).

We now make the link between our definitions of behavioral elasticities and the elasticities along a linear tax schedule used in Saez (2001). We denote the latter with a tilde. Rewriting 
(9), (10) and (7) with $T^{\prime \prime}()=$.0 yields:

$$
\begin{gathered}
\tilde{\varepsilon}_{w}=\frac{\mathcal{U}_{Y}^{\prime}}{Y_{w}\left[\mathcal{U}_{Y Y}^{\prime \prime}-2\left(\frac{\mathcal{U}_{Y}^{\prime}}{\mathcal{U}_{C}^{\prime}}\right) \mathcal{U}_{C Y}^{\prime \prime}+\left(\frac{\mathcal{U}_{Y}^{\prime}}{\mathcal{U}_{C}^{\prime}}\right)^{2} \mathcal{U}_{C C}^{\prime \prime}\right]} \quad \tilde{\eta}_{w}=\frac{\left(\frac{\mathcal{U}_{Y}^{\prime}}{\mathcal{U}_{C}^{\prime}}\right) \mathcal{U}_{C C}^{\prime \prime}-\mathcal{U}_{C Y}^{\prime \prime}}{\mathcal{U}_{Y Y}^{\prime \prime}-2\left(\frac{\mathcal{U}_{Y}^{\prime}}{\mathcal{U}_{c}^{\prime}}\right) \mathcal{U}_{C Y}^{\prime \prime}+\left(\frac{\mathcal{U}_{Y}^{\prime}}{\mathcal{U}_{c}^{\prime}}\right)^{2} \mathcal{U}_{C C}^{\prime \prime}} \\
\tilde{\alpha}_{w}=-\frac{w \cdot\left[\mathcal{U}_{Y w}^{\prime \prime} \cdot \mathcal{U}_{C}^{\prime}-\mathcal{U}_{C w}^{\prime \prime} \cdot \mathcal{U}_{Y}^{\prime}\right]}{Y_{w} \cdot\left[\mathcal{U}_{Y Y}^{\prime \prime}-2\left(\frac{\mathcal{U}_{Y}^{\prime}}{\mathcal{U}_{c}^{\prime}}\right) \mathcal{U}_{C Y}^{\prime \prime}+\left(\frac{\mathcal{U}_{Y}^{\prime}}{\mathcal{U}_{c}^{\prime}}\right)^{2} \mathcal{U}_{C C}^{\prime \prime}\right] \cdot \mathcal{U}_{C}^{\prime}}
\end{gathered}
$$

Consider now a uniform decrease $\tau$ of marginal tax rates (respectively a rise $\rho$ of the level of tax, a rise $\delta w$ in skill). Such a "reform" has a first impact on earnings $\Delta_{1} Y_{w}$ that equals:

$$
\Delta_{1} Y_{w}=\tilde{\varepsilon}_{w} \times \frac{Y_{w}}{1-T^{\prime}\left(Y_{w}\right)} \times \tau \quad \text { or } \quad \Delta_{1} Y_{w}=\tilde{\eta}_{w} \times \rho \quad \text { or } \quad \Delta_{1} Y_{w}=\tilde{\alpha}_{w} \times \frac{Y_{w}}{w} \times \delta w
$$

which in turn implies a change in marginal tax rates of $-T^{\prime \prime}\left(Y_{w}\right) \times \Delta_{1} Y_{w}$. Hence, the reform has a second impact on earnings that equals:

$$
\Delta_{2} Y_{w}=-\tilde{\varepsilon}_{w} \times \frac{Y_{w}}{1-T^{\prime}\left(Y_{w}\right)} \times T^{\prime \prime}\left(Y_{w}\right) \times \Delta_{1} Y_{w}
$$

This "circular process" takes place infinitely, with the $n^{\text {th }}$ impact on earnings being linked to the $(n-1)^{\text {th }}$ impact through:

$$
\Delta_{n} Y_{w}=-\tilde{\varepsilon}_{w} \times \frac{Y_{w}}{1-T^{\prime}\left(Y_{w}\right)} \times T^{\prime \prime}\left(Y_{w}\right) \times \Delta_{n-1} Y_{w}
$$

Using the identity $1-x+x^{2}-x^{3} \ldots=1 /(1+x)$, the total impact equals $\sum_{i=0}^{+\infty} \Delta_{i} Y_{w}=$ $\Delta_{1} Y_{w} /\left(1+\tilde{\varepsilon}_{w} \times \frac{Y_{w}}{1-T^{\prime}\left(Y_{w}\right)} \times T^{\prime \prime}\left(Y_{w}\right)\right)$. Hence $\varepsilon_{w}, \eta_{w}, \alpha_{w}, \tilde{\varepsilon}_{w}, \tilde{\eta}_{w}$ and $\tilde{\alpha}_{w}$ are linked through

$$
\frac{\varepsilon_{w}}{\tilde{\varepsilon}_{w}}=\frac{\eta_{w}}{\tilde{\eta}_{w}}=\frac{\alpha_{w}}{\tilde{\alpha}_{w}}=\frac{\sum_{i=0}^{+\infty} \Delta_{i} Y_{w}}{\Delta_{1} Y_{w}}=\frac{1}{1+\tilde{\varepsilon}_{w} \times \frac{Y_{w}}{1-T^{\prime}\left(Y_{w}\right)} \times T^{\prime \prime}\left(Y_{w}\right)}
$$

Using (5) and (29), one retrieves (9), (10) and (7).

\section{B The government's optimum}

This appendix solves the government's problem in terms of allocation, as in Mirrlees (1971), and considers the possibility of bunching. Using the obtained government's optimality conditions, we show the equivalence between this formulation and the optimal tax formula of Proposition 1.

According to the taxation principle (Hammond 1979, Rochet 1985 and Guesnerie 1995), the set of allocations induced by the tax function $T$ (.) corresponds to the set of incentive-compatible allocations $\left\{Y_{w}, C_{w}, U_{w}\right\}_{w \in\left[w_{0}, w_{1}\right]}$ that verify:

$$
\forall(w, x) \in\left[w_{0}, w_{1}\right]^{2} \quad U_{w} \equiv \mathcal{U}\left(C_{w}, Y_{w}, w\right) \geq \mathcal{U}\left(C_{x}, Y_{x}, w\right)
$$

The incentive-compatible restrictions (30) impose the condition that when taking their intensive decisions, workers of skill $w$ prefer the bundle $\left(C_{w}, Y_{w}\right)$ designed for them rather then the bundle 
$\left(C_{x}, Y_{x}\right)$ designed for workers of any other skill level $x$. We assume that $w \mapsto Y_{w}$ is continuous on $\left[w_{0}, w_{1}\right]$ and differentiable everywhere, except for a finite number of skill levels. Finally, $w \mapsto U_{w}$ is differentiable. Hence, $w \mapsto C_{w}$ is also continuous everywhere and differentiable almost everywhere. These assumptions are made for reasons of tractability and have been standard since Guesnerie and Laffont (1984) ${ }^{24}$

From Equation (2), the strict single-crossing condition holds. Hence, constraints $(30)$ are equivalent to imposing the differential equation:

$$
\dot{U}_{w} \stackrel{\text { a.e. }}{=} \mathcal{U}_{w}^{\prime}\left(C_{w}, Y_{w}, w\right)
$$

and the monotonicity requirement that the earnings level $Y_{w}$ be a nondecreasing function of the skill level $w$. We obtain:

Lemma 1 The necessary conditions for the government's problem are $2^{25}$

- if there is no bunching at skill $w$ :

$$
\left(1+\frac{\mathcal{U}_{Y}^{\prime}}{\mathcal{U}_{C}^{\prime}}\right) \cdot h(w)=Z_{w} \cdot \frac{\mathcal{U}_{Y w}^{\prime \prime} \mathcal{U}_{C}^{\prime}-\mathcal{U}_{C w}^{\prime \prime} \mathcal{U}_{Y}^{\prime}}{\mathcal{U}_{C}^{\prime}}
$$

- if there is bunching over $[\underline{w}, \bar{w}]$ :

$$
\int_{\underline{w}}^{\bar{w}}\left(1+\frac{\mathcal{U}_{Y}^{\prime}}{\mathcal{U}_{C}^{\prime}}\right) \cdot h(w) \cdot d w=\int_{\underline{w}}^{\bar{w}} Z_{w} \cdot \frac{\mathcal{U}_{Y w}^{\prime \prime} \mathcal{U}_{C}^{\prime}-\mathcal{U}_{C w}^{\prime \prime} \mathcal{U}_{Y}^{\prime}}{\mathcal{U}_{C}^{\prime}} \cdot d w
$$

For all skill levels:

$$
-\dot{Z}_{w}=\frac{\left(1-g_{w}\right) \cdot h(w)+Z_{w} \cdot \mathcal{U}_{C w}^{\prime \prime}}{\mathcal{U}_{C}^{\prime}}-\left(T\left(Y_{w}\right)+b\right) \cdot h_{U}^{\prime}(w)
$$

with $Z_{w_{1}}=Z_{w_{0}}=0$ and:

$$
\left(1-\int_{w_{0}}^{w_{1}} h(w) \cdot d w\right)\left(1-g_{0}\right)=\int_{w_{0}}^{w_{1}}\left(Y_{w}-C_{w}+b\right) \cdot h_{b}^{\prime}(w) \cdot d w
$$

Proof. Given that $\mathcal{U}(., .,$.$) is increasing in C$, we define $C_{w}$ as function $\Gamma\left(U_{w}, Y_{w}, w\right)$ such that $U=\mathcal{U}(C, Y, w)$ if and only if $C=\Gamma(U, Y, w)$. We obtain

$$
\Gamma_{U}^{\prime}=\frac{1}{\mathcal{U}_{C}^{\prime}} \quad \Gamma_{Y}^{\prime}=-\frac{\mathcal{U}_{Y}^{\prime}}{\mathcal{U}_{C}^{\prime}} \quad \Gamma_{w}^{\prime}=-\frac{\mathcal{U}_{w}^{\prime}}{\mathcal{U}_{C}^{\prime}}
$$

where the functions are evaluated at $(w, C=\Gamma(u, Y, w), u=\mathcal{U}(C, Y, w), Y)$, Next, we rewrite (31) as $\dot{U}_{w}=\Psi\left(U_{w}, Y_{w}, w\right)$, where

$$
\Psi(U, Y, w) \stackrel{\text { def }}{\equiv} \mathcal{U}_{w}^{\prime}(\Gamma(U, Y, w), Y, w)
$$

One has from $(36)$ :

$$
\Psi_{Y}^{\prime}=\frac{\mathcal{U}_{Y w}^{\prime \prime} \mathcal{U}_{C}^{\prime}-\mathcal{U}_{C w}^{\prime \prime} \mathcal{U}_{Y}^{\prime}}{\mathcal{U}_{C}^{\prime}} \quad \Psi_{U}^{\prime}=\frac{\mathcal{U}_{C w}^{\prime \prime}}{\mathcal{U}_{C}^{\prime}}
$$

\footnotetext{
${ }^{24}$ Hellwig (2008) explains how the same first-order conditions can be obtained under weaker assumptions on $w \mapsto Y_{w}$ and $w \mapsto U_{w}$.

${ }^{25}$ where the various derivatives of $\mathcal{U}$ are evaluated at $\left(C_{w}, Y_{w}, w\right)$.
} 
where the functions are evaluated at $\left(w, C_{w}, U_{w}, Y_{w}\right)$. We consider $Y_{w}$ as the control variable and $U_{w}$ as the state variable. Then $\lambda$ equals the Lagrange multiplier associated with the budget constraint (13). Let $q_{w}$ be the costate variable associated to (31) and let $Z_{w}=-q_{w} / \lambda$. The Hamiltonian writes:

$$
\begin{aligned}
& \mathcal{H}(Y, U, q, w, \lambda) \stackrel{\text { def }}{=} \int_{0}^{U_{w}-\mathcal{U}(b, 0, w)} G\left(U_{w}-\chi, w, \chi\right) \cdot k(\chi, w) \cdot d \chi \cdot f(w) \\
& +\int_{U_{w}-\mathcal{U}(b, 0, w)}^{+\infty} G(\mathcal{U}(b, 0, w), w, \chi) \cdot k(\chi, w) \cdot d \chi \cdot f(w)-\lambda \cdot(b+E) \cdot f(w) \\
& +\lambda\left[Y_{w}-\Gamma\left(U_{w}, Y_{w}, w\right)+b\right] \cdot h(w)+q_{w} \cdot \Psi\left(U_{w}, Y_{w}, w\right)
\end{aligned}
$$

The first-order conditions of the government's program are:

- If there is no bunching at skill $w$, one must have:

$$
0=\frac{\partial \mathcal{H}}{\partial Y}\left(Y_{w}, U_{w}, q_{w}, w, \lambda\right)=\lambda\left[1-\Gamma_{Y}^{\prime}\right] \cdot h+q_{w} \cdot \Psi_{Y}^{\prime}
$$

Using $Z_{w}=-q_{w} / \lambda, 36$ and (37) leads to 32).

- If there is bunching over $[\underline{w}, \bar{w}]$, one must have $\int_{\underline{w}}^{\bar{w}} \partial \mathcal{H} / \partial Y\left(Y_{w}, U_{w}, q_{w}, w, \lambda\right) \cdot d w=0$. Using again $Z_{w}=-q_{w} / \lambda$ (36) and (37) gives 33.

- The transversality conditions are $q_{w_{0}}=q_{w_{1}}=0$ and, for any skill level where $w \mapsto Y_{w}$ is continuous, one obtains $-\dot{q}_{w}=\partial \mathcal{H} / \partial U\left(Y_{w}, U_{w}, q_{w}, w, \lambda\right)$. Using $Z_{w}=-q_{w} / \lambda$ and (15) gives (34).

- Finally, the first-order condition with respect to $b$ gives 35 .

We now show how to retrieve the formula in Proposition 1. Let:

$$
X_{w}=Z_{w} \cdot \exp \left[\int_{w_{0}}^{w} \Psi_{U}^{\prime}\left(U_{x}, Y_{x}, x\right) \cdot d x\right] \quad \text { and } \quad J_{w}=Z_{w} \cdot \mathcal{U}_{C}^{\prime}\left(C_{w}, Y_{w}, w\right)
$$

$Z_{w}$ and $J_{w}$ have the same sign as $X_{w}$. As $w \mapsto Z_{w}, w \mapsto X_{w}$ is moreover differentiable with a derivative:

$$
\dot{X}_{w}=\left[\dot{Z}_{w}+Z_{w} \cdot \Psi_{U}^{\prime}\left(U_{w}, Y_{w}, w\right)\right] \cdot \exp \left[\int_{w_{0}}^{w} \Psi_{U}^{\prime}\left(U_{x}, Y_{x}, x\right) \cdot d x\right]
$$

Therefore, from (11), (34) and (37):

$$
-\dot{X}_{w}=\left\{1-g_{w}-\kappa_{w} \cdot\left(T\left(Y_{w}\right)+b\right)\right\} \cdot \frac{h(w)}{\mathcal{U}_{C}^{\prime}\left(C_{w}, Y_{w}, w\right)} \cdot \exp \left[\int_{w_{0}}^{w} \Psi_{U}^{\prime}\left(U_{x}, Y_{x}, x\right) \cdot d x\right]
$$

At skill levels for where there is no bunching, Equation (32) can be rewritten using (5), 28b) and $(28 \mathrm{c})$ as:

$$
T^{\prime}\left(Y_{w}\right) \cdot h(w)=Z_{w} \cdot \mathcal{Y}_{w}^{\prime}=J_{w} \cdot \frac{\mathcal{Y}_{w}^{\prime}}{\mathcal{Y}_{\tau}^{\prime}}
$$

Using (7), (9) 28b and 28c we obtain:

$$
\frac{T^{\prime}\left(Y_{w}\right)}{1-T^{\prime}\left(Y_{w}\right)} \cdot h(w)=J_{w} \cdot \frac{\alpha_{w}}{\varepsilon_{w} \cdot w}
$$


From (34) and (11) we obtain:

$$
\begin{aligned}
\dot{J}_{w}= & -\left\{1-g_{w}-\kappa_{w} \cdot\left(T\left(Y_{w}\right)+b\right)\right\} \cdot h(w)-Z_{w} \cdot \mathcal{U}_{C w}^{\prime \prime}\left(C_{w}, Y_{w}, w\right) \\
& +Z_{w}\left\{\mathcal{U}_{C C}^{\prime \prime}\left(C_{w}, Y_{w}, w\right) \dot{C}_{w}+\mathcal{U}_{C Y}^{\prime \prime}\left(C_{w}, Y_{w}, w\right) \cdot \dot{Y}_{w}+\mathcal{U}_{C w}^{\prime \prime}\left(C_{w}, Y_{w}, w\right)\right\}
\end{aligned}
$$

Assume now that the tax function is everywhere differentiable and there is no bunching. Differentiating $C_{w}=Y_{w}-T\left(Y_{w}\right)$ and using (5) gives:

$$
\begin{aligned}
\dot{J}_{w}= & -\left\{1-g_{w}-\kappa_{w} \cdot\left(T\left(Y_{w}\right)+b\right)\right\} \cdot h(w) \\
& +Z_{w}\left\{\mathcal{U}_{C Y}^{\prime \prime}\left(C_{w}, Y_{w}, w\right)-\mathcal{U}_{C C}^{\prime \prime}\left(C_{w}, Y_{w}, w\right) \frac{\mathcal{U}_{Y}^{\prime}\left(C_{w}, Y_{w}, w\right)}{\mathcal{U}_{C}^{\prime}\left(C_{w}, Y_{w}, w\right)}\right\} \cdot \dot{Y}_{w}
\end{aligned}
$$

Using (28c), 28d and again (5):

$$
\dot{J}_{w}=-\left\{1-g_{w}-\kappa_{w} \cdot\left(T\left(Y_{w}\right)+b\right)\right\} \cdot h(w)+J_{w} \cdot \frac{\mathcal{Y}_{\rho}^{\prime}}{\mathcal{Y}_{\tau}^{\prime}} \cdot \dot{Y}_{w}
$$

With (7), (9), (10), 28c and 28d :

$$
\dot{J}_{w}=-\left\{1-g_{w}-\kappa_{w} \cdot\left(T\left(Y_{w}\right)+b\right)\right\} \cdot h(w)+J_{w} \cdot \frac{\eta_{w} \cdot \alpha_{w}}{\varepsilon_{w} \cdot w}\left(1-T^{\prime}\left(Y_{w}\right)\right)
$$

Finally, using (39):

$$
\dot{J}_{w}=-\left\{1-g_{w}-\kappa_{w} \cdot\left(T\left(Y_{w}\right)+b\right)\right\} \cdot h(w)+\eta_{w} \cdot T^{\prime}\left(Y_{w}\right) \cdot h(w)
$$

Given $Z_{w_{1}}=0, J_{w_{1}}=0$, so $J_{w}=\int_{w}^{w_{1}}\left(-\dot{J}_{n}\right) d n$. Using the last equation and 39 gives 17 . Equation (18) is obtained from the transversality condition $J_{w_{0}}=0$. Equation (19) is obtained by adding (35) to (18).

\section{Proof of Proposition 2}

We return back to the case where $w \mapsto\left(C_{w}, Y_{w}\right)$ is continuous everywhere and differentiable everywhere except on a finite number of skill levels (so that bunching can occur on a finite number of skill intervals). Note that continuity of $w \mapsto Y_{w}$ implies that $w \mapsto U_{w}$ is continuously differentiable. We first show the following.

Lemma $2 X_{w}$ (thereby $Z_{w}$ ) is everywhere nonnegative and almost everywhere positive within $\left(w_{0}, w_{1}\right)$ whenever $w \mapsto \frac{1-g_{w}}{\kappa_{w}}$ is increasing.

Proof. Assume by contradiction that $Z_{w^{\prime}} \leq 0$ for some $w^{\prime} \in\left(w_{0}, w_{1}\right)$. Then $X_{w^{\prime}} \leq 0$. Through the continuity of $w \mapsto X_{w}$, and the transversality condition there exists a maximal interval $\left[w_{2}, w_{3}\right]$ where $X_{w} \leq 0$ for all $w \in\left[w_{2}, w_{3}\right]$ and $X_{w_{2}}=X_{w_{3}}=0$. Moreover, as $w \mapsto C_{w}$ is also continuous everywhere and differentiable almost everywhere, $X_{w}$ is everywhere differentiable with a derivative given by $(38)$.

- Given $X_{w_{2}}=0$ and $X_{w} \leq 0$ in the right neighborhood of $w_{2}$, one must have $\dot{X}_{w_{2}} \leq 0$. Hence, from (38):

$$
\frac{1-g_{w_{2}}}{\kappa_{w_{2}}} \geq T\left(Y_{w_{2}}\right)+b
$$


- Given $X_{w_{3}}=0$ and $X_{w} \leq 0$ in the left neighborhood of $w_{3}$, one must have $\dot{X}_{w_{3}} \geq 0$. By a symmetric reasoning, this leads to:

$$
T\left(Y_{w_{3}}\right)+b \geq \frac{1-g_{w_{3}}}{\kappa_{w_{3}}}
$$

- One has:

$$
T(w)+b=Y_{w}-\Gamma\left(U_{w}, Y_{w}, w\right)
$$

Function $w \mapsto Y_{w}-\Gamma\left(U_{w}, Y_{w}, w\right)$ is continuous and, except at a finite number of points, differentiable with derivative:

$$
\begin{aligned}
& \frac{d\left(Y_{w}-\Gamma\left(U_{w}, Y_{w}, w\right)\right)}{d w}=\dot{Y}_{w}\left(1-\Gamma_{Y}^{\prime}\left(U_{w}, Y_{w}, w\right)\right)-\Gamma_{U}^{\prime}\left(U_{w}, Y_{w}, w\right) \cdot \dot{U}_{w}-\Gamma_{w}^{\prime}\left(U_{w}, Y_{w}, w\right) \\
& =\dot{Y}_{w}\left(1+\frac{\mathcal{U}_{Y}^{\prime}\left(U_{w}, Y_{w}, w\right)}{\mathcal{U}_{C}^{\prime}\left(U_{w}, Y_{w}, w\right)}\right)-\frac{\mathcal{U}_{w}^{\prime}\left(C_{w}, Y_{w}, w\right)}{\mathcal{U}_{C}^{\prime}\left(C_{w}, Y_{w}, w\right)}+\frac{\mathcal{U}_{w}^{\prime}\left(C_{w}, Y_{w}, w\right)}{\mathcal{U}_{C}^{\prime}\left(C_{w}, Y_{w}, w\right)}=\dot{Y}_{w}\left(1+\frac{\mathcal{U}_{Y}^{\prime}\left(U_{w}, Y_{w}, w\right)}{\mathcal{U}_{C}^{\prime}\left(U_{w}, Y_{w}, w\right)}\right)
\end{aligned}
$$

where the second equality follows $(31)$ and (36). If there is bunching at $w$, then $\dot{Y}_{w}=0$. If there is no bunching at $w$, then Equation (32) applies. Condition (2) and $Z_{w} \leq 0$ then induce that $w \mapsto Y_{w}-\Gamma\left(U_{w}, Y_{w}, w\right)$ admits a nonpositive derivative. Hence, $w \mapsto$ $Y_{w}-\Gamma\left(U_{w}, Y_{w}, w\right)$ is weakly decreasing over $\left[w_{2}, w_{3}\right]$, so:

$$
T\left(Y_{w_{2}}\right)+b \geq T\left(Y_{w_{3}}\right)+b
$$

Inequalities 40, 41) and 42) imply:

$$
\frac{1-g_{w_{2}}}{\kappa_{w_{2}}} \geq \frac{1-g_{w_{3}}}{\kappa_{w_{3}}}
$$

This is consistent with the assumption that $w \mapsto\left(1-g_{w}\right) / \kappa_{w}$ is increasing if and only if $w_{2}=w_{3}$. Therefore $w^{\prime}=w_{2}=w_{3}$ and $X_{w^{\prime}} \geq 0$ for all skill levels and $X_{w}=0$ only pointwise.

Given that $X_{w}$ (hence $Z_{w}$ ) is nonnegative everywhere and can be nil only pointwise, then for skill levels where there is no bunching, according to (5) and (32), the marginal tax rate is nonnegative and can be nil only pointwise. Bunches of skills correspond to a mass point of the earnings distribution and to an upward discontinuity in the marginal tax rates. However, the discontinuity is between two marginal tax rates that correspond to skill levels without bunching for which we have shown that the marginal tax rates are nonnegative.

\section{Proof of Proposition 3}

Given that $X_{w_{0}}=0$ and for all $w, X_{w} \geq 0$ (from Proposition 2), then $\dot{X}_{w_{0}} \geq 0$. According to (38), this induces:

$$
\frac{1-g_{w_{0}}}{\kappa_{w_{0}}} \leq T\left(Y_{0}\right)+b
$$

As $g_{w_{0}} \leq 1$, the left-hand side is positive, inducing that in-work benefit (i.e. $-T\left(Y_{0}\right)$ when $\left.T\left(Y_{0}\right)<0\right)$ is lower than welfare benefit $b$. From Proposition 2, we get for any $w T\left(Y_{w}\right)+b \geq$ $T\left(Y_{w}\right)+b \geq 0$. 


\section{E Proofs of Properties 1 and 2}

Under (27), $U_{w}$ is increasing in skill $w$. Then, a Maximin government values only the welfare of the nonemployed and $g_{w}=0$ for all skill levels, which ensures property 2 for a Maximin government.

Under (26), $\mathcal{U}_{C}^{\prime}$ depends only on the consumption level. From (2), incentive-compatible conditions 30 imply that $w \mapsto C_{w}$ is nondecreasing. Therefore, as $u_{C C}^{\prime \prime}<0, w \mapsto \mathcal{U}_{C}^{\prime}\left(C_{w}, Y_{w}, w\right)$ is nondecreasing, and increasing without bunching.

Under (26) and a Benthamite government, $g_{w}$ simply equals $\mathcal{U}_{C}^{\prime}\left(C_{w}, Y_{w}, w\right) / \lambda$ according to (15), which ensures property 2 for a Benthamite government.

Under Assumption (27), one has that the threshold value $U_{w}-\mathcal{U}(b, 0, w)$ of $\chi$ below which individuals of type $(w, \chi)$ choose to work, is decreasing in skill level $w$. So, when $K(\chi, w)$ is strictly log-concave with respect to $\chi$ and $w \mapsto k(\chi, w) / K(\chi, w)$ is nonincreasing in $w$, then $w \mapsto k\left(U_{w}-\mathcal{U}(b, 0, w), w\right) / K\left(U_{w}-\mathcal{U}(b, 0, w), w\right)$ is decreasing. Together with $w \mapsto$ $\mathcal{U}_{C}^{\prime}\left(C_{w}, Y_{w}, w\right)$ being nondecreasing, using (11) ensures that $w \mapsto \kappa_{w}$ is decreasing, even in the presence of bunching. Consequently, Property 1 is ensured.

\section{E.1 Example 1}

A Maximin government values only the welfare of the nonemployed, so $g_{w}=0$ for all skill levels and $\left(1-g_{w}\right) / \kappa_{w}=1 / \kappa_{w}$. As Property 1 holds, $\left(1-g_{w}\right) / \kappa_{w}$ is therefore increasing in $w$ and Proposition 2 applies. Moreover, as $g_{w}=0$, Proposition 3 also applies.

\section{E.2 Example 2}

Combining Properties 1, 2 and $g_{w} \leq 1$ ensures that $\left(1-g_{w}\right) / \kappa_{w}$ is increasing in $w$. As a result, Proposition 2 applies, and thereby Proposition 3 as it has been assumed that $g_{w} \leq 1$.

\section{References}

[1] Atkinson, T., 1990, Public Economics and the Economic Public, European Economic Review, 34(2-3), 225-248.

[2] Blomquist, S. and L. Simula, 2010, Marginal Deadweight Loss when the Income Tax is Nonlinear, Working Paper Uppsala Universitet 2010:3.

[3] Boadway, R. and L. Jacquet, 2008, Optimal Marginal and Average Income Taxation under Maximin, Journal of Economic Theory, 143(1), 425-41.

[4] Boone, J. and L. Bovenberg, 2004, The optimal taxation of unskilled labour with job search and social assistance, Journal of Public Economics, 88(11), 2227-58.

[5] Choné, P. and G. Laroque, 2005, Optimal incentives for labor force participation, Journal of Public Economics, 89(2-3), 395-425.

[6] Choné, P. and G. Laroque, 2009a, Optimal Taxation in the extensive model, IFS working paper $08 / 08$.

[7] Choné, P. and G. Laroque, 2009b, Negative marginal tax rates and heterogeneity, American Economic Review, forthcoming and IFS Working Paper 09/12. 
[8] Christiansen, V., 1981, Evaluation of public projects under optimal taxation, Review of Economic Studies, 48(3), 447-57.

[9] Diamond, P., 1975, A many-person Ramsey tax rule, Journal of Public Economics, 4(4), $335-42$.

[10] Diamond, P., 1980, Income Taxation with Fixed Hours of Work, Journal of Public Economics, 13(1), 101-10.

[11] Diamond, P, 1998, Optimal Income Taxation: An Example with a U-Shaped Pattern of Optimal Marginal Tax Rates, American Economic Review, 88(1), 83-95.

[12] Guesnerie, R., 1995, A Contribution to the Pure Theory of Taxation, Cambridge University Press, Cambridge.

[13] Guesnerie, R. and Laffont, J-J, 1984, A complete solution to a class of principal-agent problems with an application to the control of a self-managed firm, Journal of Public Economics, $\mathbf{2 5}(3), 329-69$.

[14] Hammond, P., 1979, Straightforward Individual Incentive Compatibility in Large Economies, Review of Economic Studies, 46(2), 263-82.

[15] Heckman, J., 1993, What Has Been Learned about Labor Supply in the Past Twenty Years?, American Economic Review, 83(2), 116-21.

[16] Hellwig, M., 2007, A contribution to the theory of optimal utilitarian income taxation, Journal of Public Economics, 91(7-8), 1449-77

[17] Hellwig, M., 2008, A Maximum Principle for Control Problems with Monotonicity Constraints, Preprints of The Max Planck Institute for Research on Collective goods Bonn, 2008-04, http://www.coll.mpg.de/pdf_dat/2008_04online.pdf.

[18] Immervoll, H., Kleven, H., Kreiner, C. T. and Saez, E., 2007, Welfare reforms in European countries: a Microsimulation analysis, Economic Journal, 117(516), 1-44.

[19] Jacobs, B. (2010), The Marginal Cost of Public Funds is One, mimeo Erasmus University Rotterdam.

[20] Juhn, C., Murphy K. M., Topel R. H., Yellen J. L. and Baily M. N., 1991, Why has the Natural Rate of Unemployment Increased over Time?, Brookings Papers on Economic Activity, 1991(2), 75-142.

[21] Kleven, H. J. and C. T. Kreiner, 2006, The Marginal Cost of Public Funds: Hours of Work versus Labor Force Participation, Journal of Public Economics, 90(10-11), 1955-73.

[22] Kleven, H. J., C. T. Kreiner and E. Saez, 2009, The Optimal Income Taxation of Couples, Econometrica, $\mathbf{7 7}(2), 537-60$.

[23] Meghir C. and D. Phillips, 2008, Labour Supply and Taxes, IZA discussion paper 3405.

[24] Mirrlees, J., 1971, An Exploration in the Theory of Optimum Income Taxation, Review of Economic Studies, 38(2), 175-208. 
[25] Piketty, T., 1997, La redistribution fiscale face au chômage, Revue Française d'Economie, 12(1), 157-201.

[26] Polachek, S. W. and W. S. Siebert, 1993, The Economics of Earnings, Cambridge University Press.

[27] Revecz, J., 1989, J.T. The optimal taxation of labour income, Public Finance, 44(4), 453-75.

[28] Revecz, J., 2003, Comparing elasticities-based optimal income tax formulas, Public Finance, 53(3-4), 470-79.

[29] Roberts, K., 2000, A Reconsideration of the Optimal Income Tax, in Incentives and Organization: Essays in Honour of Sir James Mirrlees, (Hammond and Myles, eds.), Oxford University Press, Oxford.

[30] Rochet, J-C, 1985, The taxation principle and multi-time Hamilton-Jacobi Equations, Journal of Mathematical Economics, 14(2), 113-28.

[31] Rochet, J-C and L. Stole, 2002, Nonlinear Pricing with Random Participation, Review of Economic Studies, 69(1), 277-311.

[32] Sadka, E., 1976, On income distribution, incentive effects and optimal income taxation, Review of Economic Studies, 43(2), 261-67.

[33] Saez, E., 2000, Optimal Income Transfer Programs:Intensive Versus Extensive Labor Supply Responses, NBER Working Paper 7708.

[34] Saez, E, 2001, Using Elasticities to Derive Optimal Income Tax Rates, Review of Economics Studies, 68(1), 205-29.

[35] Saez, E., 2002, Optimal Income Transfer Programs: Intensive Versus Extensive Labor Supply Responses, Quarterly Journal of Economics, 117(3), 1039-73.

[36] Saez,E., 2003, Reply on comparing elasticities-based optimal income tax formulas by John T. Revesz, Public Finance, 53(3-4) (2003) 480-85.

[37] Saez, E., Slemrod, J. and S. Giertz, 2010, The Elasticity of Taxable Income with Respect to Marginal Tax Rates: A Critical Review, http://elsa.berkeley.edu/ saez/saez-slemrodgiertzJEL10round3.pdf.

[38] Salanié, B., 2003, The Economics of Taxation, MIT Press.

[39] Sandmo, A., 1998, Redistribution and the marginal cost of public funds, Journal of Public Economics, 70(3), 365-82.

[40] Seade, J., 1977, On the shape of optimal tax schedules, Journal of Public Economics, 7(2), 203-35.

[41] Seade, J., 1982, On the sign of the optimum marginal income tax, Review of Economic Studies, 49(2), 637-43.

[42] Werning, I., 2000, An Elementary Proof of Positive Optimal Marginal Taxes, mimeo MIT. 


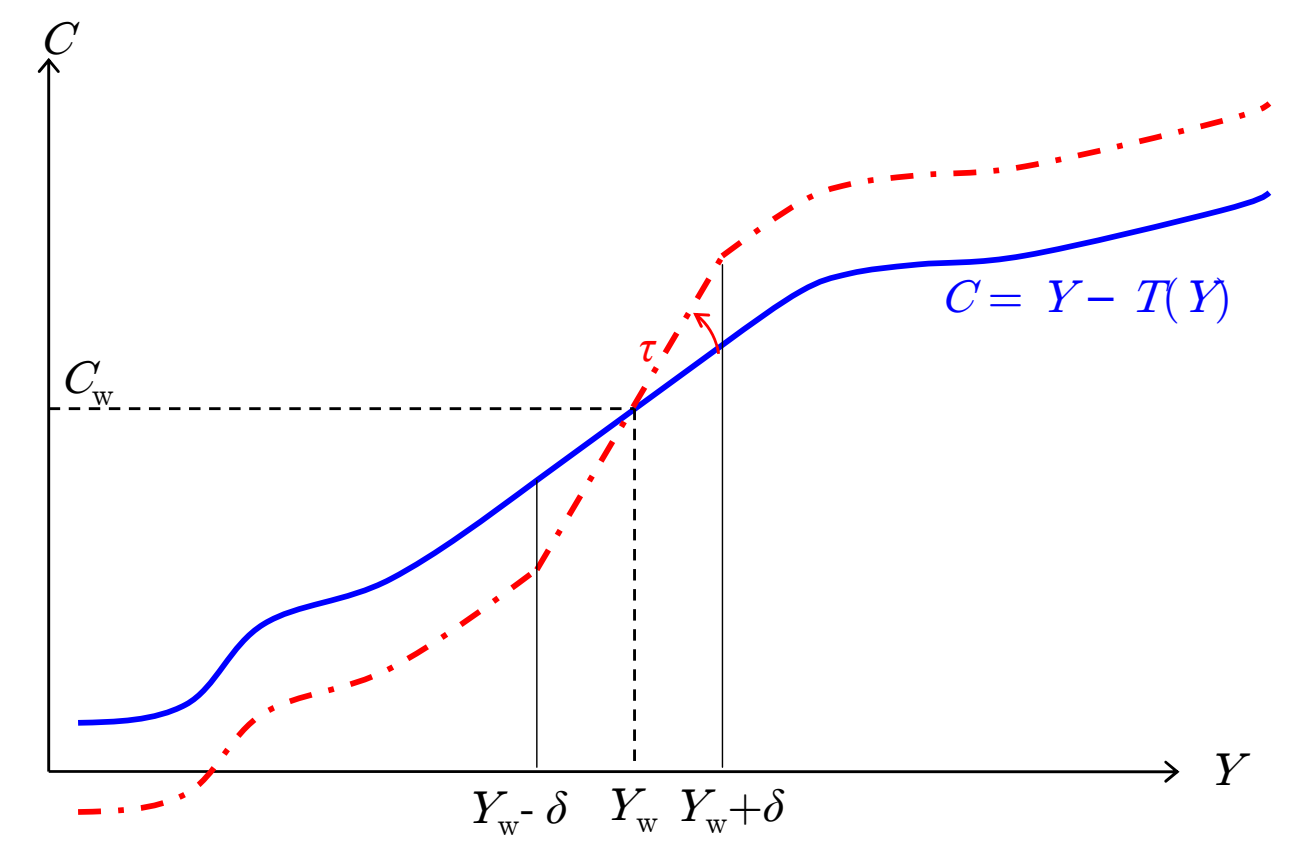

An infinitesimal reform of the marginal tax rate

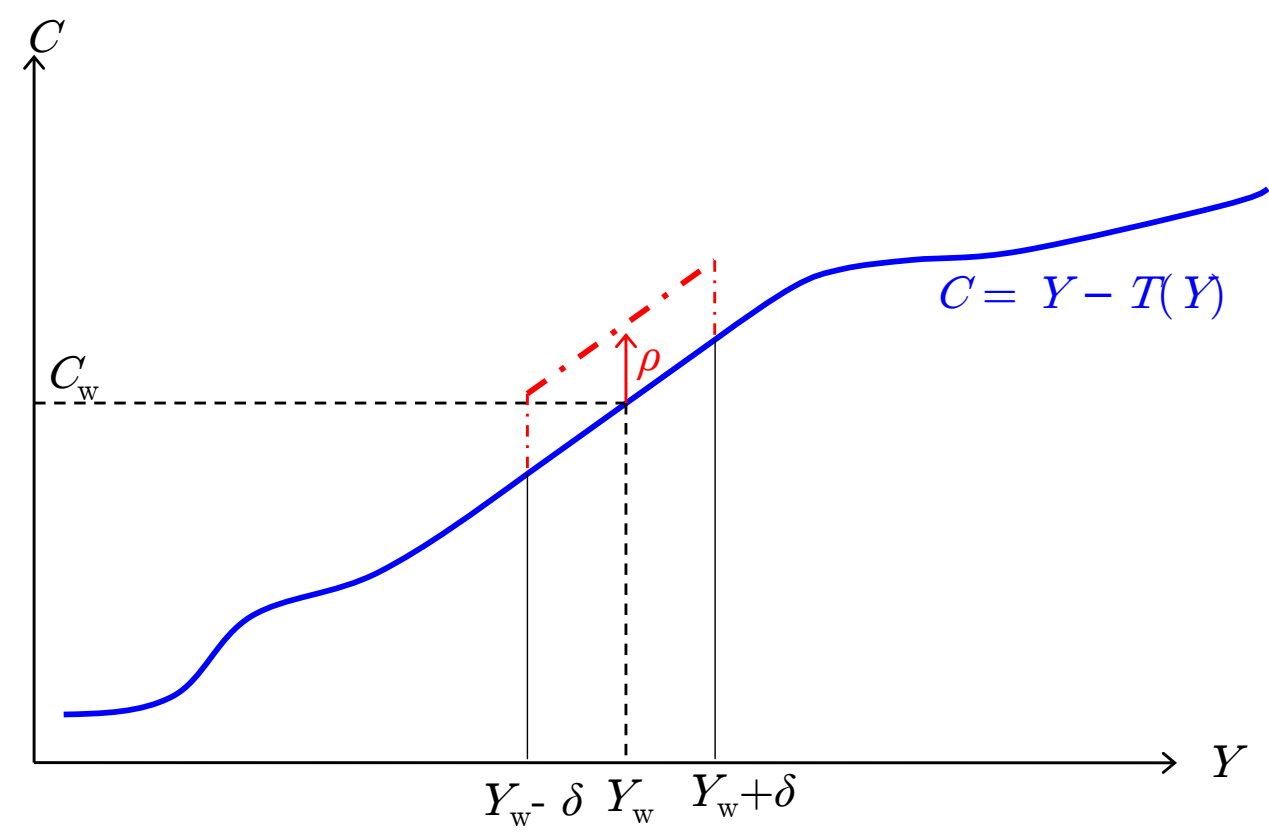

An infinitesimal reform of the tax level

Figure 1: Tax reforms around $Y_{w}$ defining behavioral responses $\varepsilon_{w}$ and $\alpha_{w}$ 


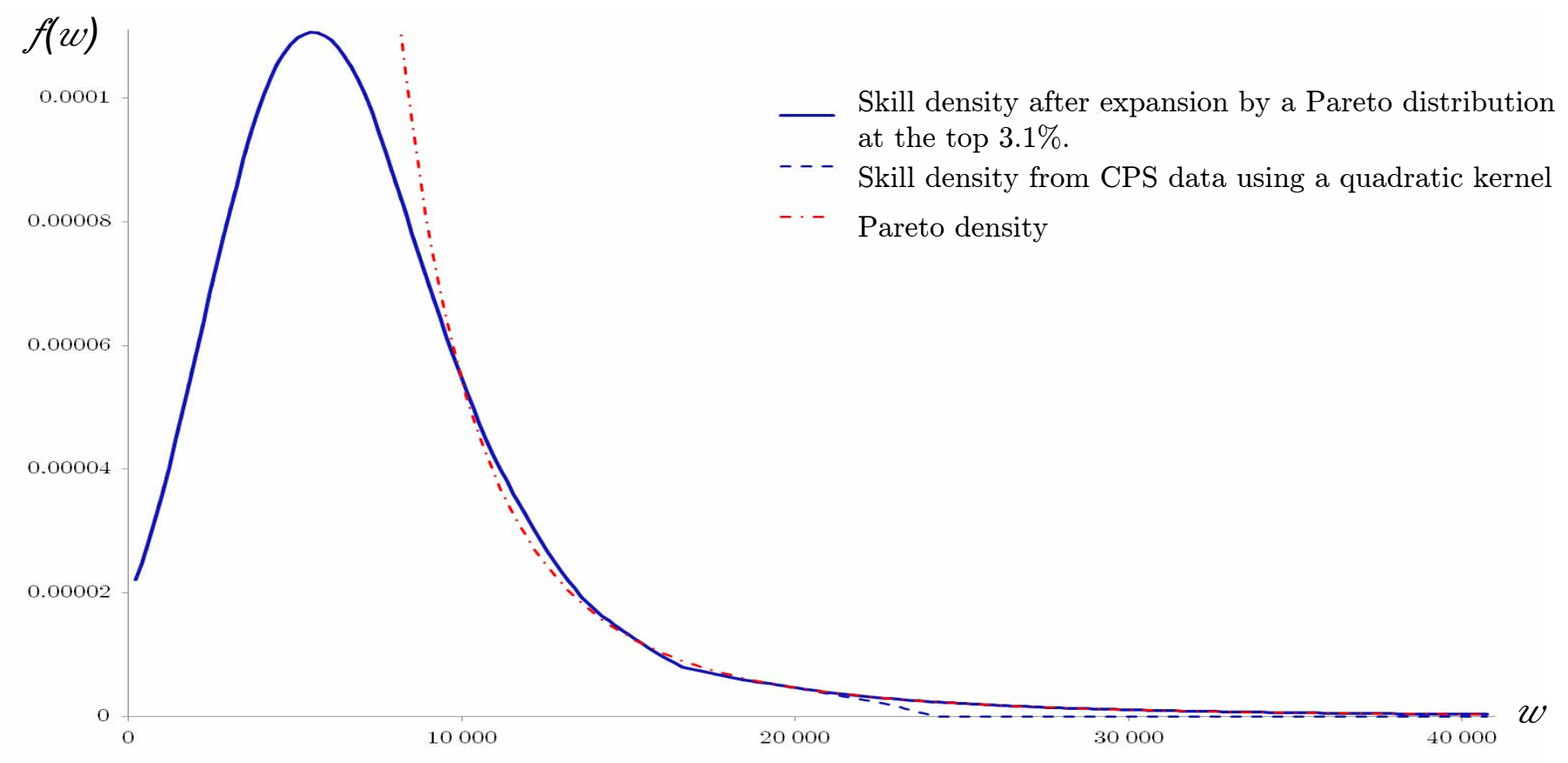

Figure 3: Skill density from the CPS data after expansion by a Pareto at the top $3.1 \%$. 


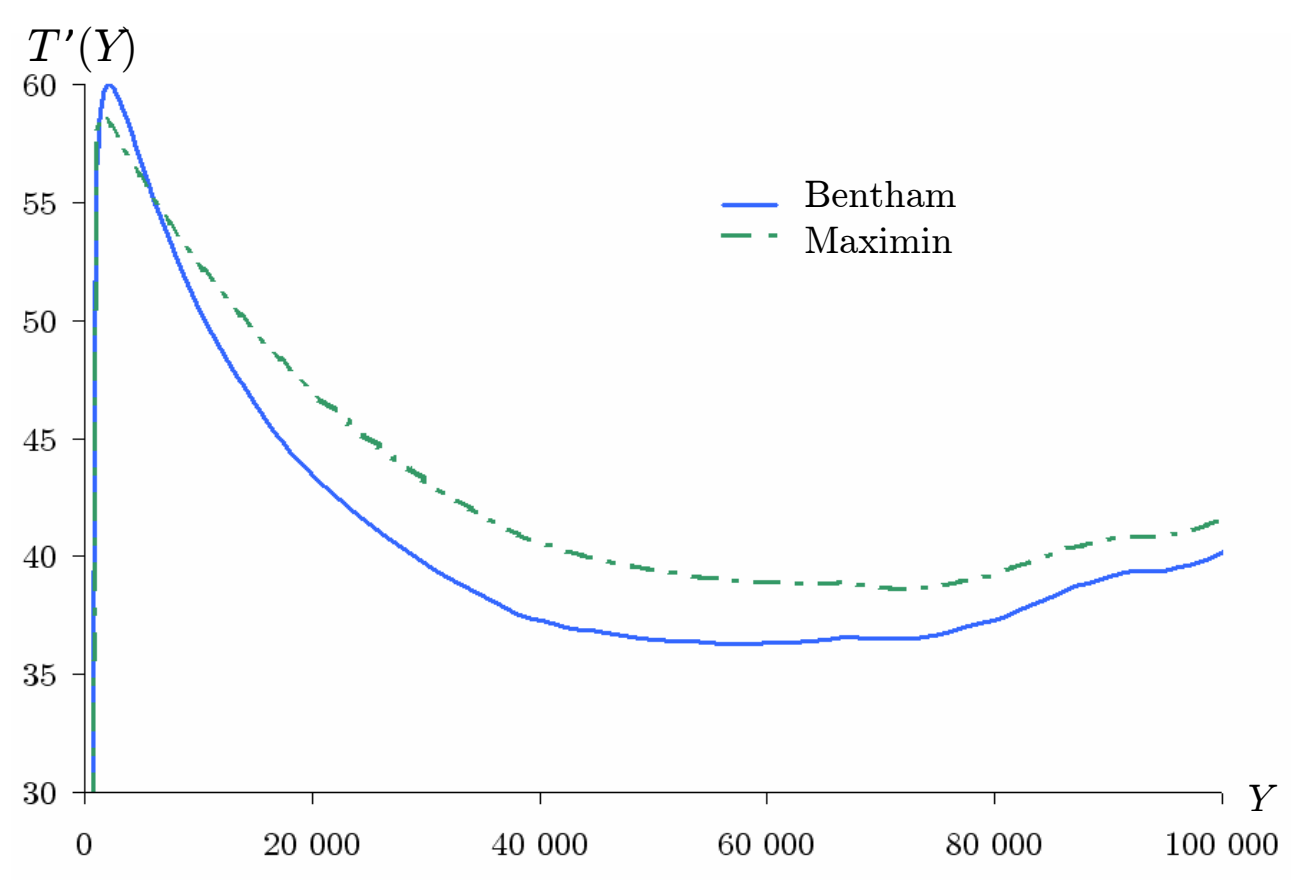

(a) Marginal Tax Rates

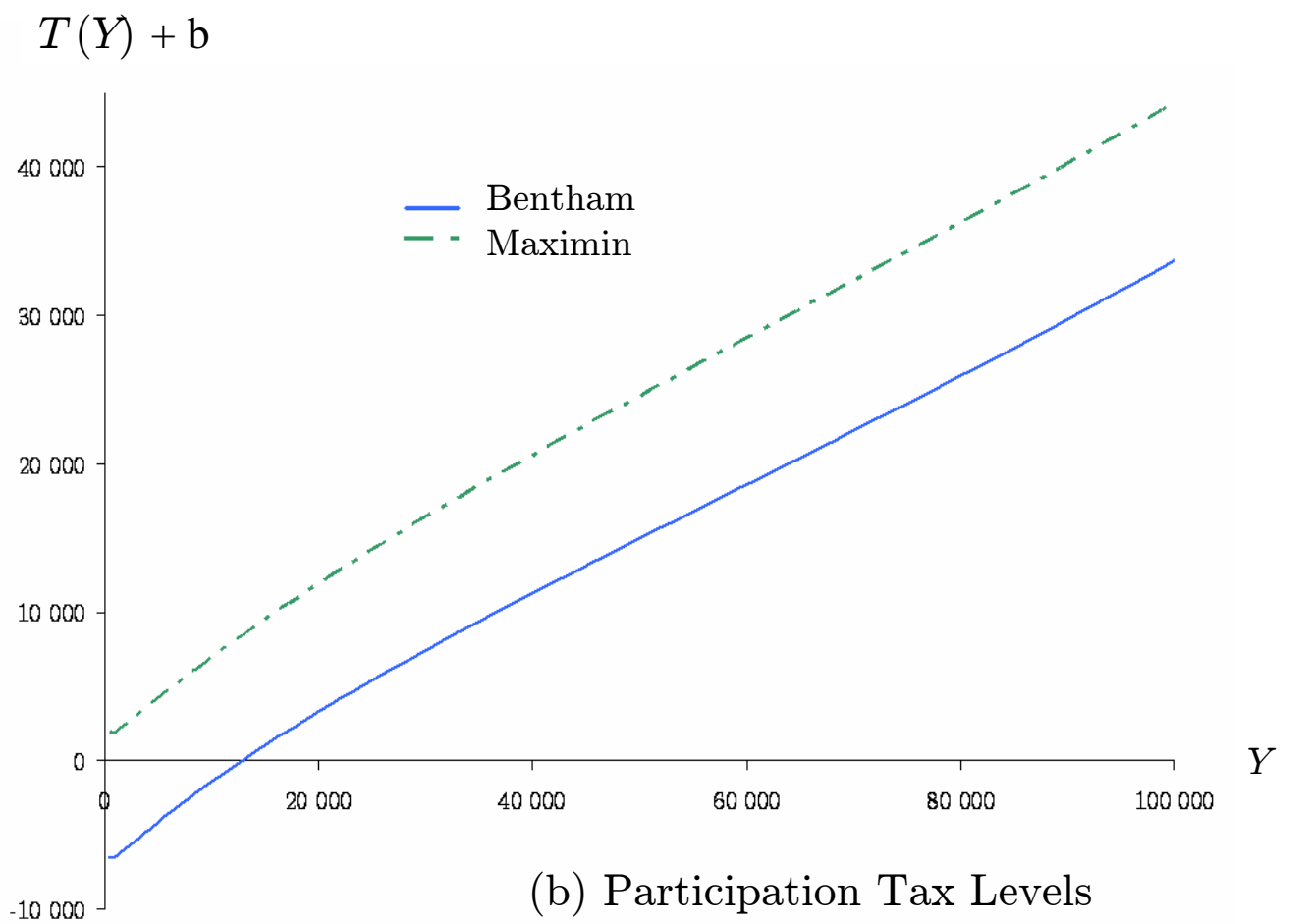

$-10000$

(b) Participation Tax Levels

Figure 4: The simulations under the benchmark calibration 
Skill specific

employment rate

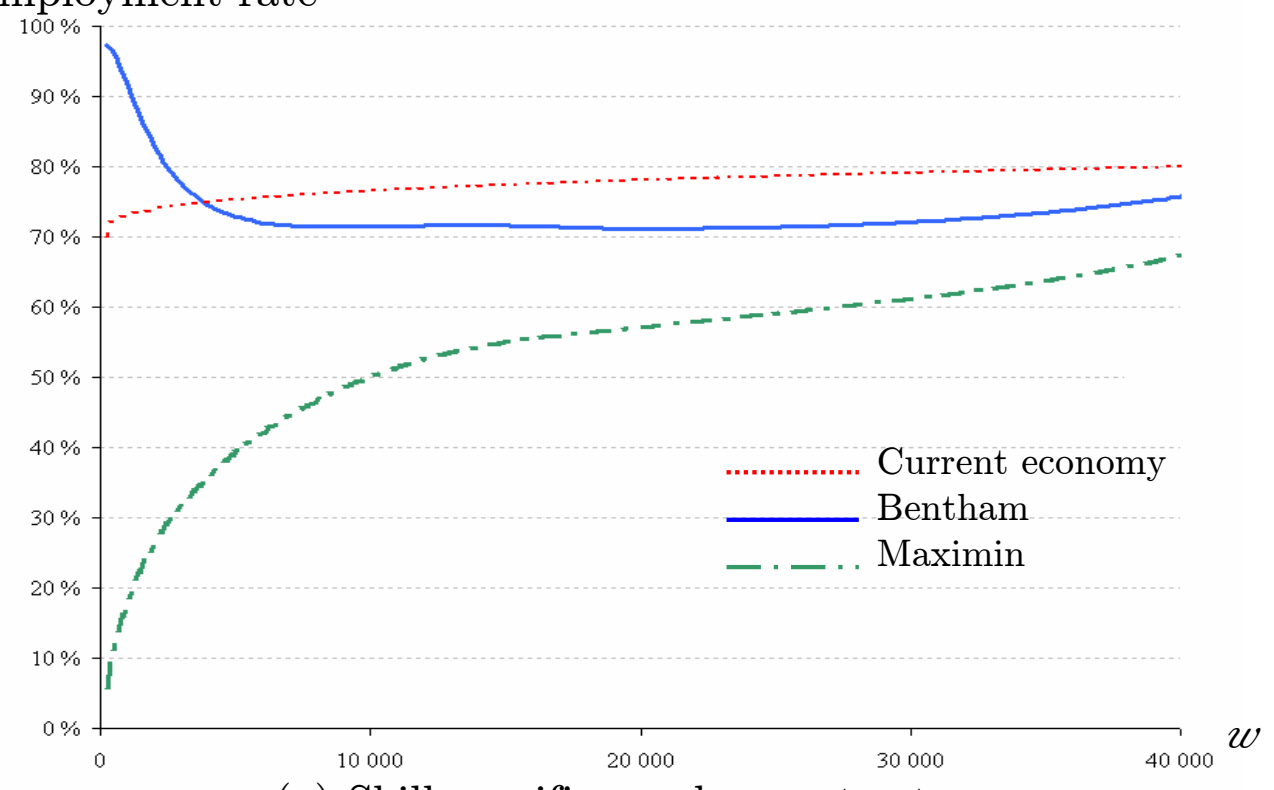

(a) Skill specific employment rates

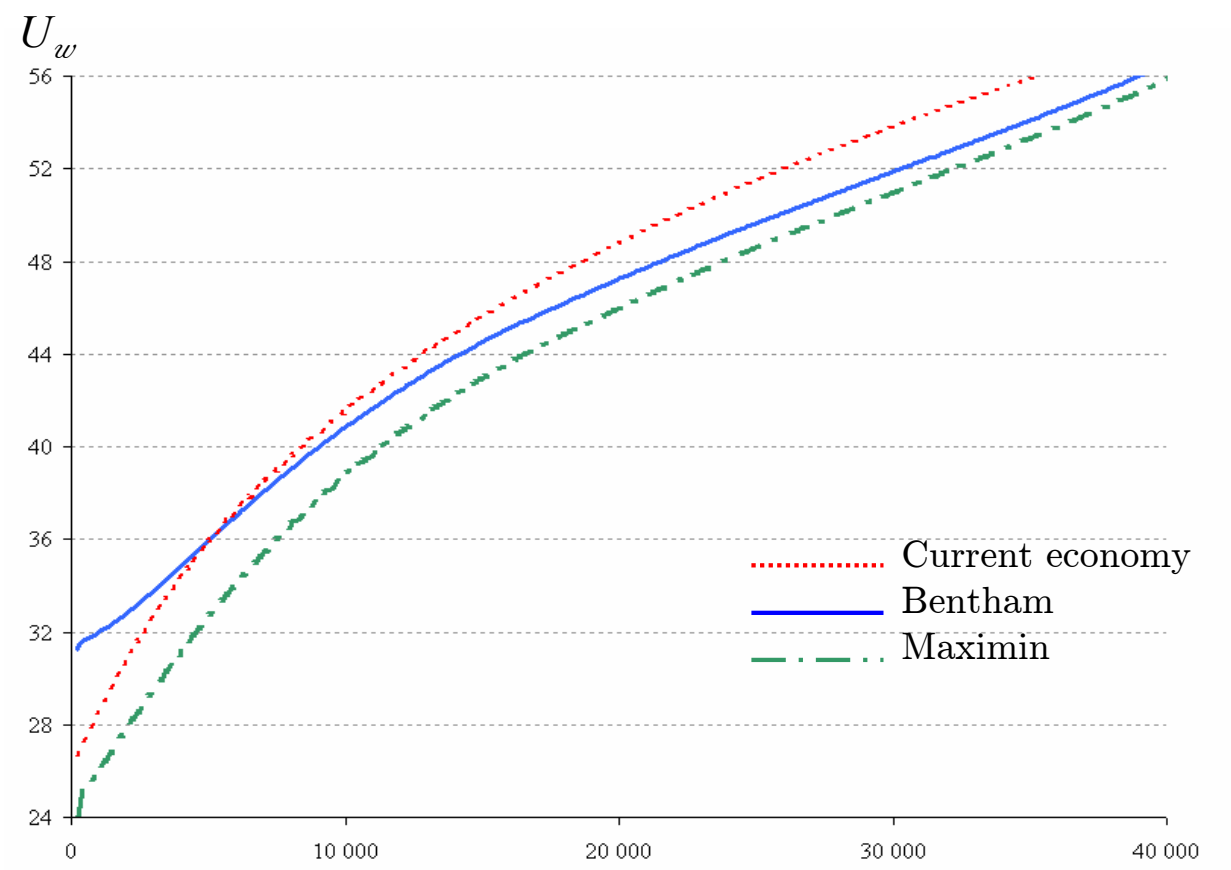

$w$

Figure 5: Optimal allocations 


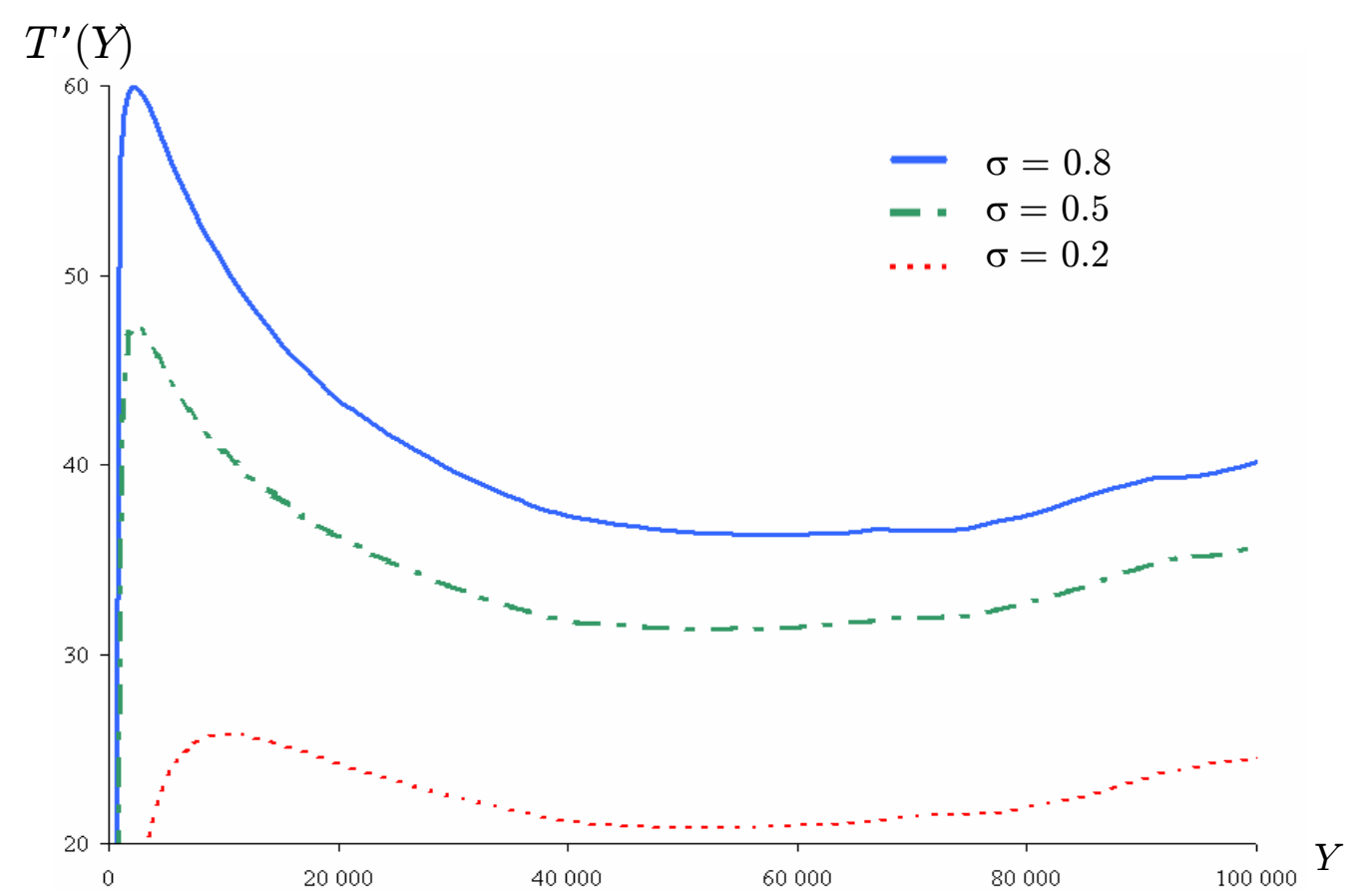

(a) Marginal Tax Rates

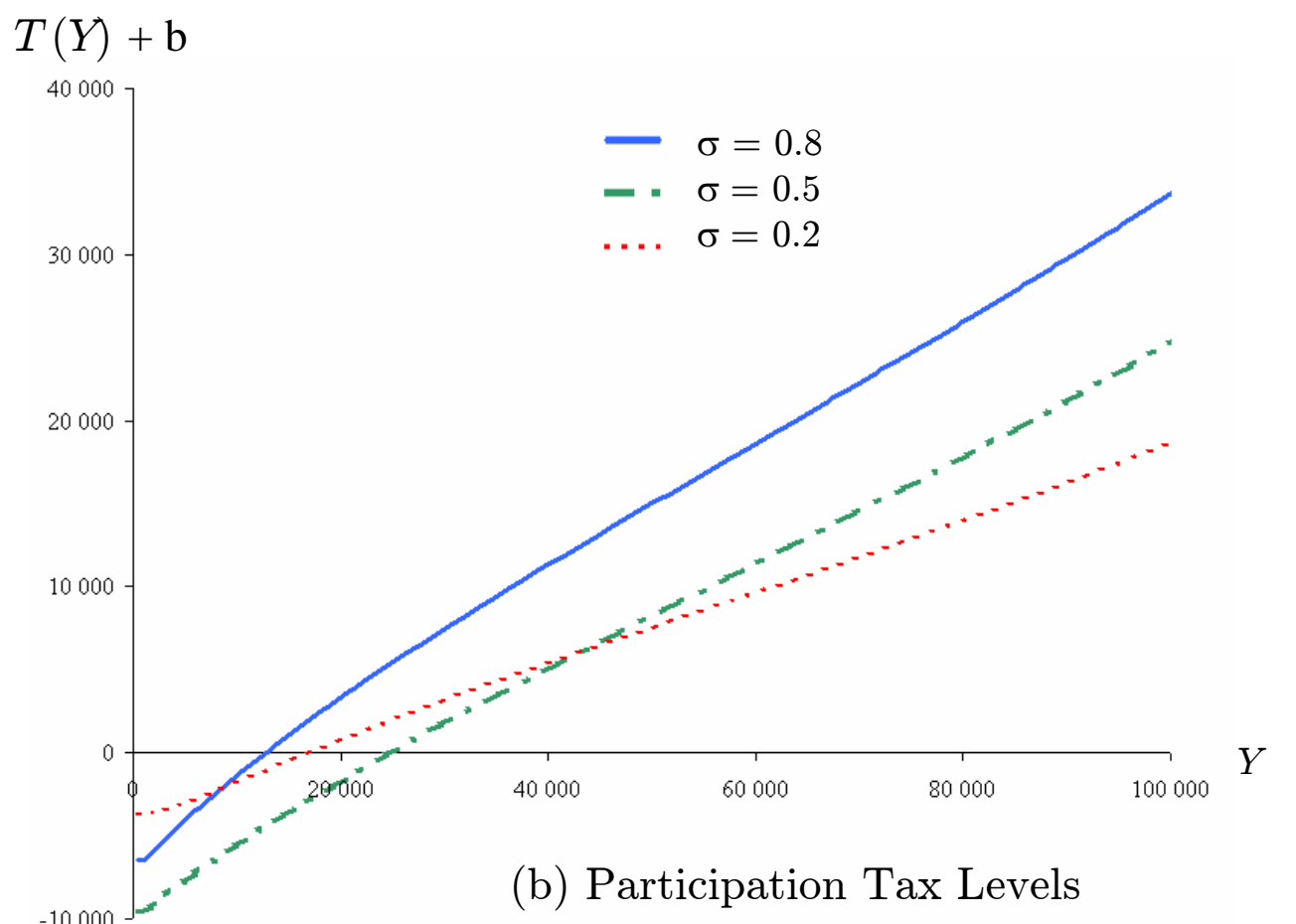

Figure 7: Sensitivity analysis with respect to $\sigma$ for the Benthamite optimum 
